\title{
Working together: the roles of geographic proximity, homophilic organizational characteristics, and neighborhood context in civic stewardship collaboration networks in Philadelphia and New York City
}

\author{
Lorien Jasnv $^{1}$, Michelle Johnson $^{2}$, Lindsav K. Campbell $^{2}$, Erika Svendsen $^{2}$ and Josh Redmond ${ }^{1}$
}

\begin{abstract}
We examine networks of collaboration among civic environmental stewardship organizations in Philadelphia and New York City to understand which factors shape collaborative ties between organizations. Environmental issues in cities are increasingly complicated and often involve many actors, including citizens, governments, and organizations. Organizations frequently collaborate to tackle collective action problems related to environmental management. Here, we study two such networks collected as part of the U.S. Forest Service's Stewardship Mapping and Assessment (STEW-MAP) project that monitors and maps the organizational characteristics of local environmental groups. We apply Exponential Random Graph models to demonstrate that network motifs, spatial proximity, organizational attributes, neighborhood context, and main issue focus all play different roles in explaining organizational collaboration among civic groups, but in very different ways across the two cities. Our findings reveal that civic networks are more correlated with homophily by social issues in Philadelphia, whereas civic networks in New York City are often correlated with geography proximity and homophily in land use. The comparative framework, still relatively rare in studies of environmental stewardship organizations, shows that different types of homophily, corresponding to different theoretical motivations, are at work in these cities. We conclude with some speculation as to the causes of these differences and their implications.
\end{abstract}

Key Words: comparative analysis; ERGM; organizational networks; stewardship; STEWMap

\section{INTRODUCTION}

Civic environmental stewardship is on the rise in many cities and regions throughout the world. Civic stewardship groups range from informal groups of friends or neighbors to professionalized nongovernmental organizations (NGOs) who engage in conserving, managing, monitoring, educating about, or advocating for the local environment (Fisher et al. 2012). Increasingly, environmental actors in these areas work within collaborative, networked structures to accomplish their goals and objectives (Gibbs and Jonas 2000, Berardo and Scholz 2010, Ernstson et al. 2010, Newig et al. 2010, Bodin et al. 2017, Groce et al. 2018). Organizational networks are important mechanisms for groups to share information and resources that can strengthen capacity and outcomes and address environmental problems frequently too complex or at too large a scale for any one organization to tackle alone (Lubell et al. 2010, Ingold and Fischer 2014). These collaborative networks often lead to new and innovative forms of governance over shared environmental resources and ecosystem services (Connolly et al. 2013, Mountjoy et al. 2013, Campbell 2017). At the same time, not all environmental groups engage equally in collaborative networks and, as a result, some groups may have less access to ideas, materials, and resources over time (Meyer and Hyde 2004, Berardo 2014). In our paper, we focus on the ways in which homophily, the tendency for organizations with similar characteristics to be more likely to work together (McPherson et al. (2001), predicts social structure; we examine proximity through geographic space, organizational characteristics, and neighborhood context. Each of these types of homophily is understood in the literature to represent different kinds of underlying processes. Understanding these patterns is a first step in both understanding the structure and function of these networks as well as their potential for effective stewardship.
Currently, empirical social network analyses of environmental management often focus on a single network (Groce et al. 2018; see a call to move beyond single networks in Bodin et al. 2016, and a rare example of comparative work in Henning et al. 2019), yet city context is known to affect variable relationships (Pierre 2005). To understand generalized patterns and neighborhood context effects, multiple networks must be compared. Cross-city comparisons can be challenging because of differences in methodology and variables collected, as well as difficulty in obtaining the network data for even one location. In this paper, we examine civic environmental stewardship networks in two cities, Philadelphia and New York City. The intent is to understand the role of neighborhood context on collaborative ties between civic organizations. We hypothesize that neighborhood context, defined here as the socioeconomic and land-use characteristics of a neighborhood, may affect the likelihood of a collaborative tie between two civic organizations, as well as interact with other factors that influence collaboration such as social and spatial proximity. We demonstrate that network motifs, spatial proximity, and homophily in organizational attributes, neighborhood context, and main issue focus all positively correlate with organizational collaboration, but in different combinations across the two cities. We examine these networks using exponential random graph (ERG) models and qualitatively compare results for the two cities' civic environmental stewardship networks. We conclude with the implications of these differences both for the networks themselves and for theories of network homophily in organizations.

\section{Network effects}

Previous research suggests that relational network effects like popularity and clustering may create the conditions that foster collaboration and exchange among environmental groups (Ernstson et al. 2010, Lubell et al. 2010, Fischer and Jasny 2017, 
Groce et al. 2018). Popularity, in networks terms, would mean that some organizations simply are preferred partners and the fact that they have many collaborators means that that preferentially attract others (Newman 2001). Clustering is the idea that organizations tend to introduce their collaborators to each other (just as in Granovetter's concept of the "forbidden triad"; see Granovetter 1977) thus forming dense, interconnected clusters in the network made up of organizations who all work together. Most critically, researchers have looked for the role of homophily in predicting organizational collaboration. These similar characteristics can span all kinds of different attributes from geography to the goals of the organization (Fischer and Jasny 2017) and beyond.

\section{Spatial effects}

Earlier work on urban environmental stewardship networks found that the location of a group's administrative office may play a role in current and future collaboration (Howells 2002, Belaire et al. 2011), but spatial location is rarely incorporated into social network studies (Sayles and Baggio 2017). Belaire et al. (2011) have previously observed spatial effects in the context of collaboration and relationship formation between environmental organizations in the Chicago area. Groups were found to cluster around shared field sites, with a correlation between spatial and network distance, i.e., the degrees of separation between two organizations. Neighborhood and social organizational context can also interact with spatial location to affect the likelihood of collaboration (Granovetter 1973, Hall 1999, Jaroff et al. 2009). Sometimes, neighborhood associations are unlikely to collaborate with adjacent associations; the proliferation of community groups in Baltimore occurred as a result of competition for resources in lower income neighborhoods (Meyer and Hyde 2004). To add to the complexity of collaboration, researchers have found that some stewardship groups tend to focus on a single parcel or neighborhood, while other groups will span neighborhoods and operate at much larger scales (Connolly et al. 2013, 2014). Fundamentally, proximity due to overlapping work sites (referred hereafter as "turfs") or closer home offices would indicate that organizational relationships result from "induced" homophily (McPherson et al. 2001); because organizations find themselves more often in the proximity of similar organizations (with similar use of the city space), they are more likely to cooperate.

\section{Organizational characteristics}

Collaboration, or lack thereof, among organizations can be the result of organizational competencies and external factors. Organizational core competencies can include member capacity, relational capacity, organizational and programmatic capacity; differences in these characteristics between organizations can lead to power imbalances in collaborative ties over access to resources (Foster-Fishman et al. 2001, Lasker and Weiss 2003, Ingold and Fischer 2014). Other factors, such as organizational age, status, and shared funding partners have been observed by Atouba and Shumate (2015) and Berardo and Scholz (2010) to influence collaborative tie formation between NGOs because these organizations tend to form ties that were homophilous along these dimensions. This is considered "choice" homophily: organizations choose to work with others more similar to themselves because sharing these attributes facilitates trust (Kleinbaum et al. 2013).
Proximity between two organizations along social dimensions can also affect the formation of collaborative organizational ties (Henry et al. 2011, Stokes et al. 2014, Fischer and Jasny 2017). Social networks scholars frequently find that shared beliefs facilitate collaboration (Ingold and Fischer 2014, Diani et al. 2018). In contrast, when examining neighborhood association collaborations, Hyde and Meyer (2010) found only a weak connection between attitudinal consensus and effective collaboration, concluding that shared attitudes among organizational leaders are insufficient for creating stable partnerships. Their mixed-method approach enabled the identification of the most significant factors, i.e., trust, legitimacy, and the need for continued engagement, and demographic differences such as race that affect the possibility of sustained collaboration. Other external barriers to collaboration can include funder expectations and regulations (Craig 2007, Lasker and Weiss 2003), competition for resources and resulting power imbalances (Liedtka and Whitten 1998, Bayne-Smith et al. 2008, Lasker and Weiss 2003).

\section{Neighborhood context}

Additionally, neighborhood conditions may affect collaboration. Seminal research has shown neighborhood effects relative to individual-level behavior, in the context of crime and health (Sampson et al. 1997, Diez Roux 2001, Lee et al. 2017) and that neighborhood mechanisms that can affect individual-level behaviors include the absence or presence of social ties, shared norms, and routines that strengthen collective efficacy that exists among urban residents (Sampson et al. 2002). Neighborhood context may be especially relevant for place-based organizations such as environmental stewardship groups because their work is often directly tied to the physical and social infrastructure of an area (Svendsen and Campbell 2008). Most important for this study is the understanding that neighborhood context is thought to be critical for collaboration capacity (Wandersman et al. 1996). In particular, U.S. cities are not homogenous entities but rather are made up of very different types of neighborhoods; socioeconomic and environmental conditions vary across any given city. Such variation can affect individual-level behavior (Sampson et al. 2002), including volunteer participation (Swaroop and Morenoff 2006, Smith 1994), as well as the distribution of environmental resources (Schwarz et al. 2015). Variation between cities also is known to exist, although less studied. For example, examining organizational resources relative to neighborhood socioeconomic and racial demographics, across 331 U.S. cities, Small and McDermott (2006) found metropolitanlevel variation, in addition to neighborhood variation. The distribution of civic environmental stewardship groups is also known to vary across neighborhoods and in relationship to both neighborhood conditions, at both Census block group and neighborhood scales (Romolini et al. 2013, Johnson et al. 2019). Significant factors that relate to stewardship groups' distribution at a neighborhood scale include race, income, home ownership, and home value (Johnson et al. 2019). Relationships between socioeconomic variables and number of stewardship groups per neighborhood vary across cities, suggesting the importance of historical legacies and development patterns to understanding relationships for any given city (Hall 1999, Jaroff et al. 2009).

From the literature, it is clear that there are several factors related to place, proximity, time, and scale that can affect collaboration 
among environmental stewardship groups. In this paper, we focus on two sets of attributes related to social proximity: attributes of the organization that include paid staff, 501(c)(3) status (IRS tax exempt status for formalized nonprofits), and the geographic extent of its stewardship activities. In all of these cases, we might expect that organizations in similar circumstances might find it easier to work together. Second, we look at similarity in terms of organizational focus by issue, e.g., public health, arts, or youth. The reasoning here is that certain focus areas might be more dominant in the civic life of a particular city than in other locations. Also, it is important to note that civic life evolves over time dependent upon conditions that include social demographic change, economic development cycles, technology, and neighborhood design. This suggests that organizational network collaboration might shift depending upon the specific themes, e.g., workforce development, community development, arts, and education, that resonate at a given time and location. We compare key differences and similarities in these two cities to learn whether or not neighborhood context interacts with social and geographic proximity to create conditions favorable for collaboration.

\section{METHODS}

\section{Study areas}

We focus on civic environmental stewardship networks in Philadelphia, Pennsylvania (established 1682) and New York, New York (established 1624). New York City is the largest city in the United States, and Philadelphia is the fifth largest city in the United States. Both are postindustrial cities located in the northeastern megalopolis, with Philadelphia positioned in-between New York City and Washington, D.C. Both cities are shaped by their surroundings: New York City is a coastal city along the Atlantic Ocean and the Hudson and East rivers, while Philadelphia is located at the intersection of the Delaware and Schyulkill rivers and also influenced by tides. These two cities were chosen because there were available organizational, network, and spatial data on environmental stewardship groups that were standardized and comparable over a similar time frame. In addition, each city contains similar representative samples of groups that conserve, manage, monitor, educate, or advocate for the urban environment. Both cities contain groups that work solely in their own neighborhood as well as those that work city-wide, that focus on topics ranging from arts to youth and work on site types that include community gardens, parks, waterfront areas, rooftops, urban farms, street trees, and other green infrastructure and open space. There are conflicts and contention in both cities over the right to public green space, access, inclusion, and design. There are places where stewardship groups are working in harmony with government and the private sector and areas where they are embroiled in lawsuits or advocacy campaigns (Svendsen and Campbell 2008, Fisher and Galli 2016).

Philadelphia and New York City also have different governance structures and trajectories of greenspace and development, which affect the distribution of public green space, economic development cycles, socioeconomic condition, and the distribution of land use (Table 1). Increased demand for housing is reducing vacancy rates in New York (Mallach 2018), although the amount of vacant lots can still be high (Kremer et al. 2013). This housing demand limits the increase in community gardens in NYC. In contrast, Philadelphia has a higher number of vacant lots, some of which are being converted to community gardens (Park and Ciorici 2013) or maintained through the city's Vacant Lot Program. Intertwined with greenspace establishment and development trajectories is the governance structure of greenspace in each city. Government structures between the two cities are similarly centralized for urban greenspaces; Parks and Recreation departments in both cities manage street trees, parks, and some community gardens. Beginning with the Central Park Conservancy in the 1980 s, New York City has promulgated the park conservancy model (often structured as public-private partnerships) for many individual parks in the city, and some Philadelphia parks, including Fairmount Park, have adopted a similar approach.

Table 1. Descriptive comparison of Philadelphia and New York; demographic data drawn from same year as network data collection where possible.

\begin{tabular}{|c|c|c|}
\hline & Philadelphia & New York \\
\hline Land Area & $347.3 \mathrm{~km}^{2}$ & $789.4 \mathrm{~km}^{2}$ \\
\hline Parkland Area & $44 \mathrm{~km}^{2}{ }^{3}$ & $161.9 \mathrm{~km}^{2} 4$ \\
\hline Population Density & $4438.2 / \mathrm{km}^{2,5 \dagger}$ & $10533.09 / \mathrm{km}^{2}$ \\
\hline $\begin{array}{l}\text { Number of } 501 \mathrm{c} 3 \\
\text { organizations }\end{array}$ & $8007^{6}$ & $20,612^{7}$ \\
\hline $\begin{array}{l}\% \text { of population who } \\
\text { volunteer }\end{array}$ & $26.50 \%^{8}$ & $17.40 \%{ }^{9}$ \\
\hline $\begin{array}{l}\text { Unemployment } \\
\% \text { Land Use }^{12,13}\end{array}$ & $7.7 \%{ }^{10 \oplus}$ & $5.6 \%^{11 \#}$ \\
\hline Residential & 35.60 & 49.48 \\
\hline Commercial & 6.81 & 4.70 \\
\hline Industrial & 13.20 & 3.61 \\
\hline
\end{tabular}

${ }^{1}$ Philadelphia Department of Planning and Development 2017

${ }^{2}$ New York Department of City Planning 2018

${ }^{3}$ ParkScore $2018 a$

${ }^{4}$ ParkScore $2018 b$

${ }^{5}$ Open Data Network 2016

${ }^{6}$ 501c3 Lookup $2018 a$

${ }^{7} 501 \mathrm{c} 3$ Lookup $2018 b$

${ }^{8}$ Corporation for National and Community Service $2018 a$

${ }^{9}$ Corporation for National and Community Service $2018 b$

${ }^{10}$ United States Department of Labor Bureau of Labor Statistics $2018 a$

${ }^{11}$ United States Department of Labor Bureau of Labor Statistics $2018 b$

${ }^{\dagger}$ Data from 2013

${ }^{\ddagger}$ Data from 2008

${ }^{\S}$ Figure includes all $501 \mathrm{c} 3$ organizations, not just environmental

organizations

'Data covers entire metro area

"Annual average 2013

\#Annual average 2008

\section{Data collection}

Organizational network datasets for New York City and Philadelphia were collected using the Stewardship Mapping and Assessment Project (STEW-MAP) methodology that includes a survey of organizational characteristics, spatial turf, described here as physical location of a stewardship activity, and social networks (Svendsen et al. 2016). New York City data were collected in 2007, while Philadelphia data were collected in 2013. Specifically, the survey asked organizations to "please list the names of all of the organizations with which you collaborate regularly." These responses were then prompted with the categories of businesses, civic, government, and schools. The networks here comprise all of the responses coded as "civic" to 
match our respondent population of civic groups. We treated organizations mentioned in this survey, but not included in the set of respondents, as organizations with missing sent-ties (but observed received ties; for further discussion see Appendix 1). For these organizations, the relevant organizational characteristics (501(c)(3) status, staff size, if they have volunteers, group focus), along with office location addresses, were identified through web searches and phone calls to verify our information. For more details on the data collection, processing, and the selection of variables for analysis, see Appendix 2.

\section{Network analysis}

After data were collected, we calculated network statistics on the civic stewardship network in each of the two cities, including measures of reciprocity, centralization, and transitivity. These measures were calculated in R 3.4.1 ( $\mathrm{R}$ Core Team 2017) using the Statnet package v2016.9 (Handcock et al. 2016). In ERG models, the network of ties is the dependent variable that is modeled, exactly as in logistic regression, by the exponentiated linear combination of sufficient statistics (for an explanation of the different network terms and the independent variables see Appendix 3). Network dependence means that, unlike logistic regression, we believe that some ties depend on others. Markov chain Monte Carlo simulation is used to generate a reference distribution and calculate likelihood statistics incorporating these dependence structures into the estimation (Lusher et al. 2012).

In our survey, respondents were asked to name organizations they collaborate with. Because not all of these organizations were surveyed (but were mentioned by those who were surveyed), we have missing data in the networks. These mentioned organizations might well have collaborative ties within the network had they been surveyed. Many social network studies remove these organizations (Goodreau et al. 2009), but we have decided to keep this information and have adjusted our methods accordingly (for more information, see Appendices 1 and 2). We present neighborhood statistics for the full network (including the nonrespondents and what we will use in the ERG models), as well as the respondent-only network for comparison. Nonrespondents are unable to send ties, which affects many standard network measures like out-degree centralization and reciprocity. Our ERG model conditions on the data missing due to nonresponse, and therefore takes into account this aspect of the data collection process (see Appendix 1). However, many of the standard network statistics, like density, are difficult to compare when networks are of different sizes (Anderson et al. 1999). Instead, we present the more comparable statistics described below.

We use the measures of reciprocity, centralization, and transitivity to compare networks. Reciprocity is the tendency for organizations to reciprocate the nominations of their alters. In general, collaboration can be thought of as an undirected tie; if organization A collaborates with organization B, then necessarily organization B is also collaborating with organization A. Here, we maintain the direction of the tie and model the reported network, which adds the dimension of response and salience to our network. Even if organizations A and B collaborate, if this is only salient to one of the organizations but not the other, and therefore not reciprocated in our dataset, we preserve that asymmetry. Thus, the measure of reciprocity measures the extent to which, when an organization is named, it is also likely to reciprocate the tie. Reciprocity is scaled between 0 and 1 as the fraction of times a tie is sent that it is also reciprocated (Wasserman and Faust 1994). reserving the directionality of the tie allows us two advantages: we are able to test whether there are discrepancies in recall, for example, if larger organizations more often forget to report smaller organizations, and we are also able to control for the fact that responding organizations are able to both send and receive ties, whereas nonrespondents can only receive ties. Centralization is based on the concept that one (or several) organizations might dominate the network structure. We measure individual organizations' centrality based on in-degree (how often they are named), out-degree (how often they name others), and betweenness (how many paths of collaboration they sit on between all other organizations). Centralization then, again scaled between 0 and 1 , measures the difference between the largest centrality and the remaining nodes, normalized by the maximum possible centralization (Freeman 1978-1979). Transitivity is measured as the percentage of the time that organization A names organization $\mathrm{B}$ as a collaborator, and $\mathrm{B}$ names $\mathrm{C}$, that $\mathrm{A}$ also names $\mathrm{C}$. It is frequently thought of as a measure of bonding capital that partners of partners also work together. It is frequently thought of as a measure of bonding capital that partners of partners also work together (Henry et al. 2011, Berardo 2014).

Although these measures begin to describe the network, because they are descriptives of an inter-related and interdependent set of network ties, they cannot fully be understood separate from each other. ERG Models (Lusher et al. 2012) as a method can adequately model this interdependence, incorporate missing data due to the research design, and compare these different measures of network interaction with a whole host of other covariates. We calculated ERG models for each city's civic stewardship network to understand what network, organizational, and spatial factors help explain whether two groups collaborate together, i.e., a tie. For each tie, the presence of a factor for the sender, the receiver, or both (homophily) was analyzed as a separate independent variable in the ERG models.

Figure 1 shows the different terms used in the ERG models. The network motifs are Ties, Mutual, Anti-Indegree Centralization, and Anti-OutDegree Centralization. The Ties term functions like an intercept term in the model. This is the base probability of a tie, controlling for everything else in the model. In social networks this term is frequently negative and significant showing that the network is relatively sparse compared to a network with a $50 \%$ density. Term $\mathrm{B}$ is for mutuality. This is the tendency for ties to be reciprocal. Although collaboration, the tie measured here, is in general thought to be a reciprocal relationship (how could an organization collaborate with another organization who is not collaborating with them), as mentioned previously, we chose to keep the directionality of the tie. Unreciprocated ties can result from false negatives if the respondent forgot to mention the tie as well as disputed relationships. Given that respondents probably only name a fraction of their organization's total collaborations, high mutuality indicates that our survey is doing a decent job of adequately capturing the relationships in the network. The last two terms, for InDegree Anti-Centralization and OutDegree Anti-Centralization, look at preferential attachment or centralization. These terms are inversely measured meaning that a positive coefficient indicates the lack of preferential attachment 
or centralization. This occurs when, given every other term in the network, organizations tend to have the same number of ties on average. High centralization on in-degree would mean that certain organizations are very popular collaboration partners. High centralization on out-degree would indicate that certain organizations gave many more responses than others. If we think of collaboration as theoretically undirected, and the direction of the ties is simply a product of our survey method, then these two terms would be identical.

Fig. 1. Terms used in the exponential random graph models.

\begin{tabular}{|c|c|c|}
\hline Term & Image & Description \\
\hline Tie & $\mathrm{O} \longrightarrow \mathrm{O}$ & $\begin{array}{l}\text { Like an intercept term, the probability of a tie when } \\
\text { all other terms do not apply }\end{array}$ \\
\hline Mutual & $0 \leftrightarrow 0$ & The tendency for ties to be reciprocated \\
\hline Receiver & 0 & $\begin{array}{l}\text { The probability that an organization with a given } \\
\text { attribute is named as a partner (and therefore } \\
\text { receives the tie) }\end{array}$ \\
\hline Sender & & $\begin{array}{l}\text { The probability that an organization with a given } \\
\text { attribute is the sender of a tie }\end{array}$ \\
\hline Homophily & & $\begin{array}{l}\text { The probability that organizations matching on a } \\
\text { given attribute are both the sender and the receiver }\end{array}$ \\
\hline Tie Weight & & $\begin{array}{l}\text { How much more likely is a tie if the weight given to } \\
\text { a particular relationship, here used as either the } \\
\text { geographic distance between home offices or } \\
\text { whether their turfs overlap, is higher }\end{array}$ \\
\hline $\begin{array}{l}\text { Anti-InDegree } \\
\text { Centralization }\end{array}$ & & $\begin{array}{l}\text { The tendency for organizations named by many } \\
\text { other organizations to not receive additional } \\
\text { nominations }\end{array}$ \\
\hline $\begin{array}{l}\text { Anti- } \\
\text { OutDegree } \\
\text { Centralization }\end{array}$ & & $\begin{array}{l}\text { The tendency for an organization that has named } \\
\text { many partners to not name more }\end{array}$ \\
\hline
\end{tabular}

The remaining terms measure the effects of attributes. For each dichotomous attribute we measure some proportion of Receiver, Sender, and Homophily. Receiver terms measure how often organizations with a particular property (like paid staff or youth as a main focus) are mentioned as a collaboration partner compared to the organizations without this property. Sender terms measure how often these organizations send ties compared to others. We kept the sender terms for organizational attributes because organizations with different access to resources might have different tendencies to nominate collaboration partners. However, it is unlikely that different organizational goals similarly constrain opportunities to collaborate. We tested this but ultimately did not include these terms because their removal also helped with model convergence. The final term, Tie Weight, looks at the strength of a tie between two organizations. We fit this for the geographic variables of the distance between home offices and whether or not organizations share work sites. For the distance between home offices, this is measured in geographic degrees. If the coefficient is positive, it means the larger the distance, the more likely organizations are to be tied. The shared work site term is dichotomous with a 1 if organizations' turfs overlap and 0 otherwise. This is only defined for organizations who responded to this question. If it is positive, it means that a shared turf meant organizations were more likely to work together when they share work sites. Additional models were run (see Appendix 3 for results of multiple additive models), and results for a single ERG model for each city (the best model by AIC, but the interpretation is consistent across all models run) are presented below as a series of figures because of the number of terms in the ERG models.

\section{RESULTS}

\section{Summary network statistics}

Figure 2 shows the networks from each city superimposed over the geography (top) and using a stochastic layout (bottom). Table 2 displays summary network statistics for each city. These demonstrate that the New York City network is much larger than the Philadelphia network, with over twice the number of respondents but almost the same number of mentioned organizations who were not included in the original sample (431 in Philadelphia and 440 in New York City; Table 2).

Fig. 2. Networks for Philadelphia (left) and New York (right). The same network is shown superimposed on the geography of the city where organizational nodes are placed at their home office location (top) and using a spring-embedded network layout algorithm (bottom).

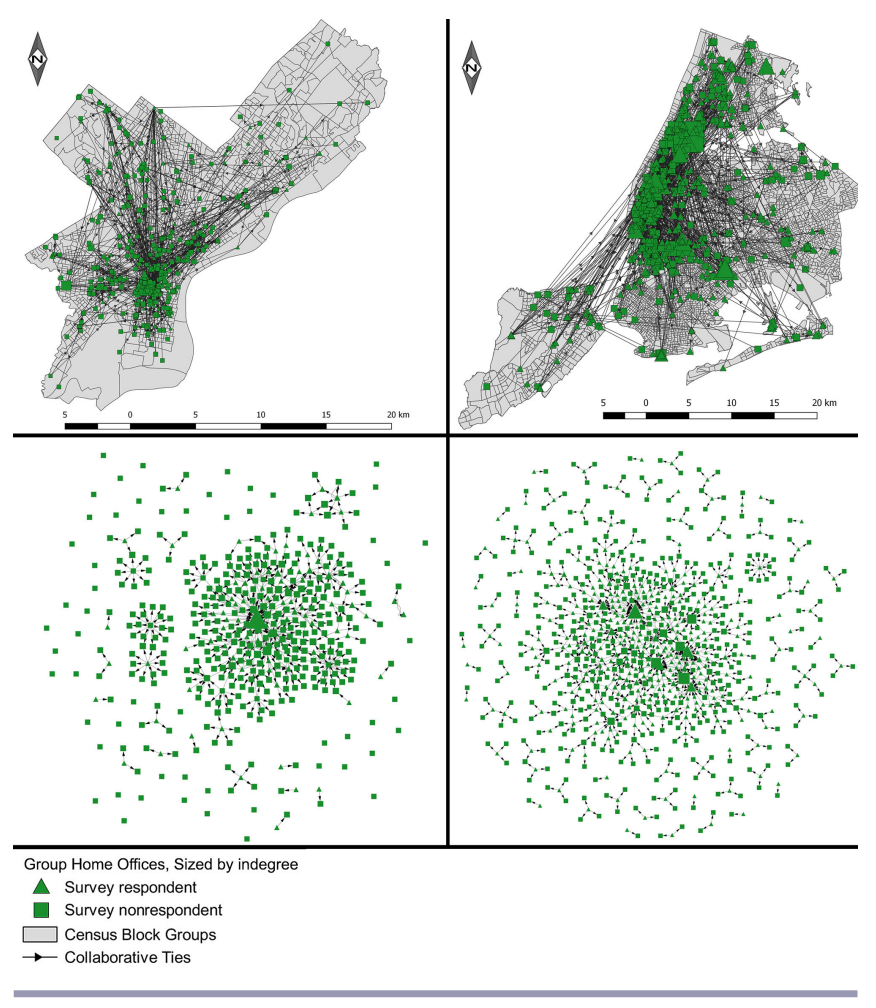

On average, Philadelphia organizations mention collaborating with more organizations than New York groups do. Philadelphia civic groups also have more mentions not just on average, but a much larger maximum as well. Philadelphia has a higher in-degree centrality in the respondent-only network (0.36) as compared with New York City (0.09), indicating some alters are mentioned very frequently as compared to the rest of the sample. This difference in comparison between the two cities disappears when calculated for the full network. The number of 0.09 is still higher than the comparison in New York $(0.04)$, but no longer an order of 
magnitude larger. Because all of the different network and attribute effects are nested and interdependent, we turn to exponential random graph models for inferential analysis.

Table 2. Network statistics for respondent and full civic environmental stewardship networks for Philadelphia and New York City.

\begin{tabular}{lccccc}
\hline \hline & \multicolumn{2}{c}{ Philadelphia } & & \multicolumn{2}{c}{ New York } \\
\cline { 2 - 3 } \cline { 5 - 6 } \cline { 5 - 6 } & Respondents & $\begin{array}{c}\text { Full } \\
\text { Network }\end{array}$ & & Respondents & $\begin{array}{c}\text { Full } \\
\text { Network }\end{array}$ \\
\hline Number of Organizations & 151 & 582 & & 335 & 775 \\
Average In-Degree & 1.05 & 1.24 & & 0.67 & 1.08 \\
Maximum In-Degree & 54 & 54 & & 29 & 29 \\
Average Out-Degree & 1.05 & 4.77 & & 0.67 & 2.49 \\
Maximum Out-Degree & 5 & 33 & & 4 & 12 \\
InDegree Centralization & 0.36 & 0.09 & & 0.09 & 0.04 \\
OutDegree Centralization & 0.03 & NA & & 0.02 & NA \\
\hline
\end{tabular}

\section{Exponential random graph models}

Separate figures highlight network and spatial terms (Figs. 3 and 4), organizational characteristic terms (Fig. 5), organizational issues (Fig. 6), and Census and land use data (Figs. 7 and 8). Most of our attributes are binary (see Table 3), but some, like the turf size, have multiple categories. For sender and receiver terms, one category is selected as a reference group and therefore omitted as is done in logistic regression. For homophily, the possible categories include a homophilic tie for each value of the variable as well as nonhomophilic ties. In most cases the nonhomophilic tie is treated as the reference group but in some cases (like with Issue Focus), terms for the homophilic tie where the attribute is absent, for example, two organizations who do not share Arts as a main focus, were also omitted. For a detailed interpretation of these results and a comparison across cities, see Appendix 3, and for a discussion of the goodness of fit for each model, see Appendix 4.

\section{Network terms}

Figure 3 is a graphical representation of the network terms in the ERG model. Interestingly, the Ties term is not significant in New York (although it is in all other models; see Appendix 3). This term is like an intercept and, as in most other social networks, the strong negative coefficient for Philadelphia indicates that the network is sparse, with a much lower density (number of edges present out of the total possible) than $50 \%$. The strong Mutual terms in both models indicate that our measure of collaboration is highly reciprocal. Ties are much more likely to occur if they are reciprocated. The next two terms are a geometrically-weighted antipopularity term meaning that a tie is less likely if the node already has many more edges. We see that this is significant for in-degrees in Philadelphia, but significant for out-degrees in New York. This means that Philadelphia has a more even spread of receivers than New York, whereas New York has a more even spread of senders than Philadelphia. However, neither city is highly central in either case, because no term is significant and negative. If we conceptualize of collaboration as an undirected tie (see Methods for a discussion of this interpretation), this indicates neither network shows any tendency toward a few organizations dominating the network.
Fig. 3. Odds ratios for Network exponential random graph (ERG) terms for Philadelphia and New York City ERG models.

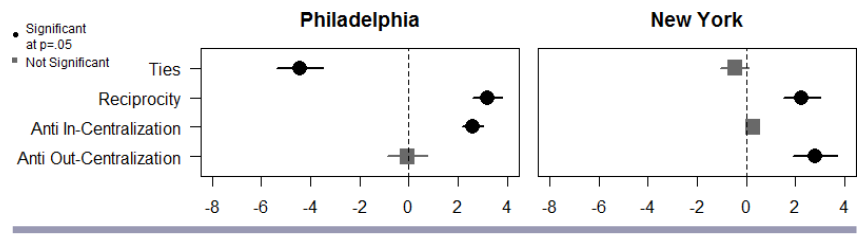

\section{Spatial terms}

In Figure 4 we see a comparison of predicting collaborative ties between two organizations based on the size of their turf, whether or not these work sites overlap, and how close their home offices are. For the Sender and Receiver terms, the reference group are those organizations whose turfs are only within one neighborhood or small worksite groups. Medium refers to turfs that span two to five neighborhoods, and large are more than five neighborhoods. We see that in both Philadelphia and New York City, organizations with medium sized turfs are mentioned as collaborative partners less than small organizations. Organizations with large turfs, however, are mentioned as frequently as organizations with small turfs. Organizations with small turfs tend not to work together in New York City (negative and significant homophily). There is no result for Philadelphia because, even though there are 44 respondents with small turfs in Philadelphia, there is only one homophilous tie among them making this term too difficult to fit in an ERG model. Additionally, in both New York City and Philadelphia, having home offices farther apart (a larger distance between them) is negatively associated with collaboration (nearer is therefore positive), but sharing a turf where the organization works is only positively associated with collaboration in New York City. These findings indicate that the home office proximity is important across cities for promoting collaboration, and that turf size factors into collaborative relationships but usually not in a homophilic sense.

Fig. 4. Odds ratios for Spatial exponential random graph (ERG) terms for Philadelphia and New York City ERG models.

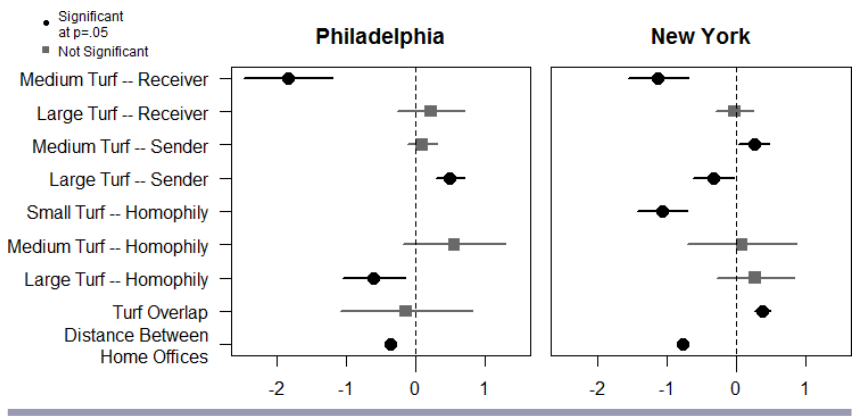

\section{Organizational terms}

Figure 5 shows the associated impact of organizational characteristics on collaborative ties. We see that being a 501(c)(3) organization in Philadelphia greatly affects collaborative potential. Overall, 501(c)(3) organizations both send and receive fewer ties, and show a significant amount of homophily. Non-501 
Table 3. Attribute data for Philadelphia and New York City civic environmental stewardship groups.

\begin{tabular}{|c|c|c|c|c|c|c|c|c|c|}
\hline & \multirow[b]{2}{*}{$\begin{array}{l}\text { How the Variable is } \\
\text { Treated }\end{array}$} & \multicolumn{4}{|c|}{ Philadelphia } & \multicolumn{3}{|c|}{ New York } & \multirow[b]{2}{*}{$\begin{array}{l}\text { Number of } \\
\text { Responses } \\
\end{array}$} \\
\hline & & Min & Mean & $\operatorname{Max}$ & $\begin{array}{l}\text { Number of } \\
\text { Responses }\end{array}$ & Min & Mean & $\operatorname{Max}$ & \\
\hline \multicolumn{10}{|l|}{ Organization Characteristics } \\
\hline $501(\mathrm{c})(3)$ & Dichotomous & 0 & 0.43 & 1 & 452 & 0 & 0.62 & 1 & 722 \\
\hline Paid Staff & Dichotomous & 0 & 0.57 & 1 & 454 & 0 & 0.6 & 1 & 634 \\
\hline Volunteers & Dichotomous & 0 & 0.83 & 1 & 464 & 0 & 0.73 & 1 & 670 \\
\hline Neighborhood Size & Categorical & 1(small) & 2.01 & 3(large) & 135 & 1 (small) & 1.62 & 3(large) & 229 \\
\hline \multicolumn{10}{|l|}{ Issues } \\
\hline Arts & Dichotomous & 0 & 0.11 & 1 & 582 & 0 & 0.23 & 1 & 775 \\
\hline Community & Dichotomous & 0 & 0.31 & 1 & 582 & 0 & 0.41 & 1 & 775 \\
\hline Development & Dichotomous & 0 & 0.11 & 1 & 582 & 0 & 0.28 & 1 & 775 \\
\hline Education & Dichotomous & 0 & 0.15 & 1 & 582 & 0 & 0.28 & 1 & 775 \\
\hline Employment & Dichotomous & 0 & 0.03 & 1 & 582 & 0 & 0.06 & 1 & 775 \\
\hline Environment & Dichotomous & 0 & 0.24 & 1 & 582 & 0 & 0.46 & 1 & 775 \\
\hline Housing & Dichotomous & 0 & 0.04 & 1 & 582 & 0 & 0.09 & 1 & 775 \\
\hline Human Services & Dichotomous & 0 & 0.05 & 1 & 582 & 0 & 0.12 & 1 & 775 \\
\hline Public Health & Dichotomous & 0 & 0.04 & 1 & 582 & 0 & 0.13 & 1 & 775 \\
\hline Recreation & Dichotomous & 0 & 0.11 & 1 & 582 & 0 & 0.15 & 1 & 775 \\
\hline Religion & Dichotomous & 0 & 0.04 & 1 & 582 & 0 & 0.04 & 1 & 775 \\
\hline Seniors & Dichotomous & 0 & 0.05 & 1 & 582 & 0 & 0.12 & 1 & 775 \\
\hline Youth & Dichotomous & 0 & 0.14 & 1 & 582 & 0 & 0.09 & 1 & 775 \\
\hline \multicolumn{10}{|c|}{ Census Data for Block of Home Office } \\
\hline Median Household Income & $\begin{array}{l}\text { Dichotomized around } \\
\text { median of } 39,861 \\
(\mathrm{PH}), 66,731 \text { (NYC) }\end{array}$ & 0 & 0.5 & 1 & 437 & 0 & 0.5 & 1 & 528 \\
\hline Median Year Moved & $\begin{array}{l}\text { Dichotomized around } \\
\text { median of } 2004 \text { (PH), } \\
2003 \text { (NYC) }\end{array}$ & 0 & 0.47 & 1 & 437 & 0 & 0.46 & 1 & 529 \\
\hline $\begin{array}{l}\text { Population Density (PH, } \\
\text { NYC) }\end{array}$ & $\begin{array}{l}\text { Dichotomized around } \\
\text { median of } 5.80 \mathrm{E} 3 \mathrm{~km}^{2} \\
(\mathrm{PH}), 1.02 \mathrm{E} 4 \mathrm{~km}^{2} \\
(\mathrm{NYC})\end{array}$ & 0 & 0.5 & 1 & 437 & 0 & 0.5 & 1 & 535 \\
\hline \multicolumn{10}{|c|}{ Land Use for Census Block of Home Office } \\
\hline $\begin{array}{l}\text { Commercial }(52,87), \\
\text { Industrial }(24,20), \text { Parks and } \\
\text { Rec }(47,41) \text {, Public Facilities } \\
(29,28), \text { Residential } \\
(237,347) \text {, Transportation } \\
(12,27)\end{array}$ & Categorical & NA & NA & NA & 550 & NA & NA & NA & 407 \\
\hline
\end{tabular}

(c)(3) organizations show negative homophily, indicating that they send more ties to 501(c)(3) organizations than themselves. Although the coefficients for these variables in New York have the same sign (negative for everything but 501(c)(3) homophily), none of the terms are significant. In Philadelphia, organizations with paid staff tend to send more ties and to show a preference for other organizations that also employ paid staff (positive homophily). In contrast, in New York organizations with no paid staff tend not to work together (negative homophily). The negative finding for staff would indicate that there is a clear preference by these organizations for partners with staffing resources. The preference is not for similar organizations, but instead for those with staff. There were no significant results for having volunteers in Philadelphia, but in New York organizations that use volunteers were less likely to be mentioned as a collaboration partner. Overall we see that 501(c)(3) status has a big impact in Philadelphia but no significant findings for New York City. In both cities organizations prefer to work with partners who have paid staff: in Philadelphia organizations with paid staff prefer partners with paid staff whereas in New York City organizations without paid staff tend to prefer partners with paid staff (as indicated by the negative finding for homophily).
Fig. 5. Odds ratios for exponential random graph (ERG) terms for Organizational Characteristics in Philadelphia and New York City ERG models.

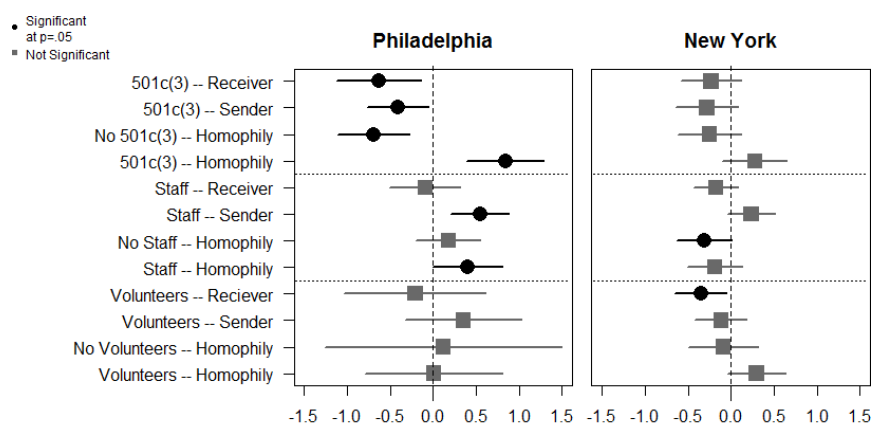

There are a number of different findings for issue focus areas, e.g., arts, youth, and social services (shown in Fig. 6), which reflect social proximity, with many more significant effects for focus areas in Philadelphia than New York (12 and 4, respectively). In 
Philadelphia, we see positive homophily effects for Arts, Community Improvement, Environment, and Religion-focused organizations. The New York network, by contrast, shows no significant effects for homophily in any category. Where we saw spatial, and thus instrumental, homophily at work in New York, these results show that issue affinity is a much stronger force in explaining the structure of the Philadelphia network.

Fig. 6. Odds ratios for Organizational Focus exponential random graph (ERG) terms for Philadelphia and New York City ERG models.

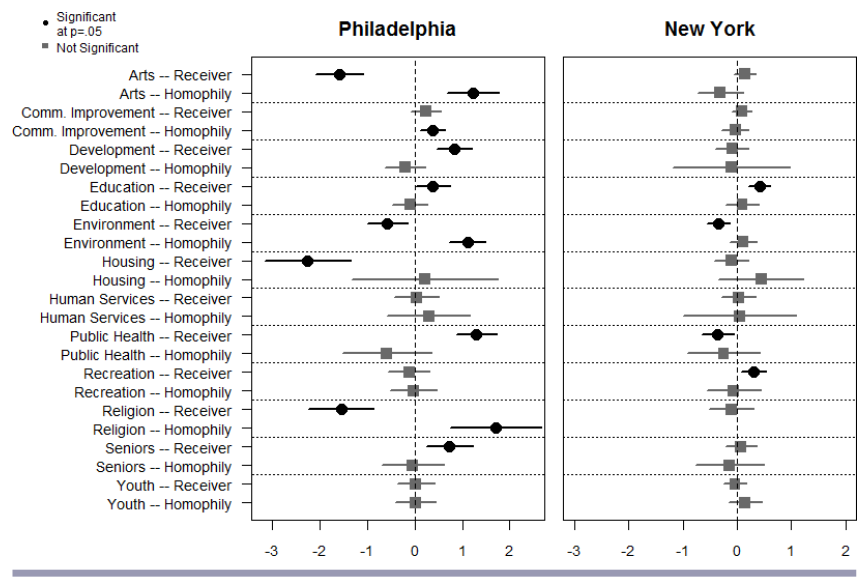

\section{Neighborhood context}

Finally, neighborhood context for the two cities also play very different roles. Figure 7 shows the results for different attributes of the Census block where the organization's home office is located. In Philadelphia, organizations in Census blocks with more recent occupants (Recent Median Year Moved) tended to be named more often but sent fewer ties on average, while in New York the only significant neighborhood context effects are that organizations in Census blocks with higher than median income and larger than median population density are less likely to nominate organizations on average. This would be consistent with an interpretation that these organizations have more resources at their disposal and thus less need to coordinate with others. Figure 8 shows results based on the land use characterization of the census block where the home office is based. In both cities there were too few homophilous ties amongst Industrial and Transportation blocks to be adequately fit by the model and had to be omitted. For other land use categories, the Philadelphia and New York networks show some distinctions based on the likelihood to be nominated but no significant homophilous effects.

\section{DISCUSSION}

Our findings show some clear similarities as well as differences between the cities; the similarities show some inherent themes that we hope future data collection will support as standard in stewardship organizational networks. In both cities the network terms show a preference for mutual ties as well as decentralized networks. However, out of the 28 significant terms in the Philadelphia and 19 in New York City (74 and 73 total model terms, respectively), only 5 of these are common across the two cities. These are: reciprocity, organizations with medium sized turfs are less likely to be mentioned compared to those with small turfs, collaboration is more likely the closer the two home offices are, education-focused organization are more often named, and finally that environmentally focused organizations are less often named. It shows plainly that organizational networks, collected with the same protocol, differ greatly by city. However, we can draw conclusions from the patterns of significances. The findings in both cities are consistent with the interpretation that collaboration is driven as much (if not more) by factors of the organizational structure, e.g., location, 501(c)(3), or paid staff, rather than the mission. This is demonstrated in the spatial finding that the distance between home offices was a better predictor than sharing turfs as well as in the lack of common significant findings in issue focus.

Fig. 7. Odds ratios for ACS Census block data for home office exponential random graph (ERG) terms for Philadelphia and New York City ERG models.

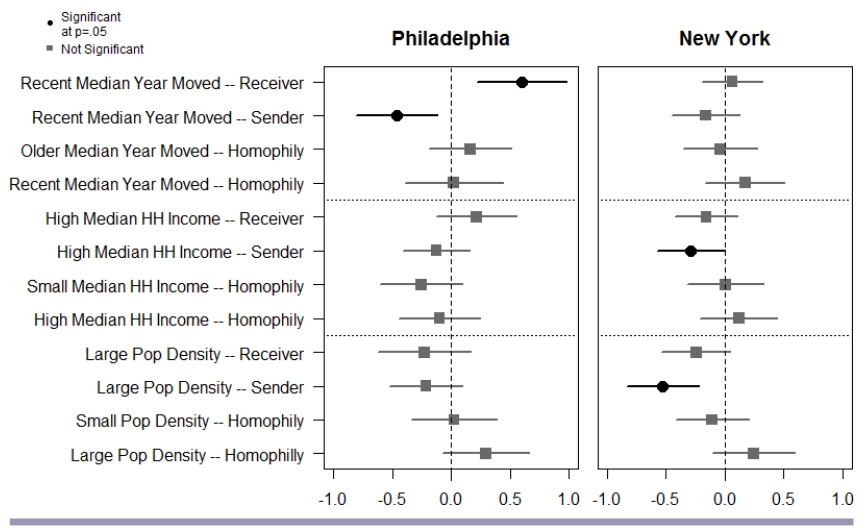

Fig. 8. Odds ratios for Census block land use exponential random graph (ERG) terms for Philadelphia and New York City ERG models.

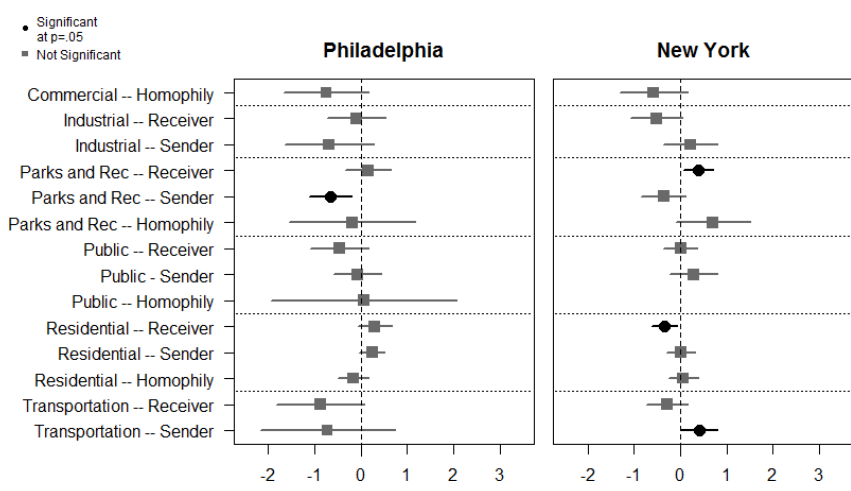

Another clear finding is that, even though the cities did not match in which terms were significant, the preponderance of homophilic terms shows that in both cities organizations demonstrated clear preferences for partners who were "like them" even if the dimensions of similarity changed by city. In Philadelphia, we see homophily in the issue focus of the organization with large effects for homophily in the arts, environment, and religion. One third of all the organizations in the network were categorized into at 
least one of these three groups. Across both cities, environmental groups are less likely to be named by other groups, suggesting that stewardship groups may aim to complement their environmental focus with partners in other sectors or fields. These findings have implications for the reach and outcomes of stewardship efforts in each city, as Philadelphia appears to have evidence of more subnetworks based on primary area of focus, e.g., public health, community development, youth, and seniors, whereas in New York, collaboration across group types appears more integrated. The historical context of how each city's governance structures have evolved may help explain why we see this difference in how groups work together. In different cities, at different times, focus areas can emerge and subside, suggesting the need for temporal network analyses to further examine the implications of focus area across any network of organizations.

Differences in our findings may be due in part to the specific geographic, social, and biophysical contexts of each city. New York City is much larger in population and area than Philadelphia, making movement across the city somewhat challenging and therefore affecting ease of collaboration. This is supported by our finding that shared turfs predicts collaboration in New York City but not in Philadelphia, where knowing the suite of actors for the entire city may be more of a possibility. Our results also suggest the geospatial extent at which group work is interrelated with the likelihood of collaboration. For both cities, organizations working only in one neighborhood are more likely to form collaborative ties than groups whose turfs span two to five neighborhoods. In other words, the most highly localized neighborhood groups work with others more often than do midsize groups that cross neighborhood boundaries, pointing to a collective interest in neighborhood stewardship as well as the possibility that these collaborations mitigate the fewer resources of smaller organizations. This second point is supported by the lack of homophily among these organizations. Where we find differences across the two cities is with the groups working at large geospatial extents: organizations working across large extents (more than five neighborhoods) collaborate with more groups in Philadelphia and fewer groups in New York City, controlling for all other factors. Further research is needed to explore this finding. From the network data alone we are unable to determine if the differences between the two cities are rooted in better adapted networks in one, or rather differing solutions to the stewardship problems faced by each city.

Comparing between the two cities highlights how differences in local economic context may affect how collaborations emerge through enabling (or constraining) different funding opportunities. In addition to the global prominence of New York City, including the presence of numerous powerful private firms and a strong philanthropic sector that serve as funders for local environmental work, is important to note that the data for New York City were collected in 2007, prior to the global financial crisis, whereas the Philadelphia data were collected in 2013, after the downturn. Our findings in organizational attributes show a clear preference in Philadelphia for organizations with more resources (as institutionalized 501(c)(3) status or paid staff). The results in New York City show similar coefficients but none are statistically significant. Only longitudinal data collection can test how susceptible these mechanisms are to economic change, and we hope this comparative work will lead to future studies.

\section{Limitations and future work}

Our study extends single network analyses, but still is limited to only two cities. Future quantitative studies can add to this effort by comparing these results to other cities, repeating this work over time to get a sense of longitudinal change, and increasing the quality of the measurement of the network. Further, this analysis has examined only civic networks, while future research will explore cross-sector collaboration among civic, private, and public sectors in order to more fully understand the structure and dynamics of the governance network. Qualitative work should focus on asking environmental stewardship organizations about their own perceptions of collaboration in light of these findings. Are these organizations aware of the patterns uncovered here in their decisions to collaborate? If so, what reasoning lies behind these different decisions in Philadelphia and New York? Our findings, particularly on the different patterns of homophilous collaboration among the two cities has opened more questions.

\section{CONCLUSION}

Theories of collaborative or networked environmental governance draw attention to the role of civic actors in governing regimes. In particular, civic stewardship groups have been shown to work independently of or alongside governmental actors, including through serving as brokers and bridging organizations among civic groups (Connolly et al. 2013). To better understand the conditions in which civic stewardship groups collaborate (or do not), there is a need for empirical measures to describe and analyze those social networks. In this paper, we have demonstrated the applicability of ERG models for analyzing social networks among civic stewards. Via this approach, we can take into account organizational characteristics, geographic space, and sociocultural context for their influence on collaboration. We find that, indeed, organizational characteristics do matter, such as formalization as a registered 501(c)(3) nonprofit organization. However, these networks are not only socially produced, they are socio-spatial as well, given that the neighborhood context of the office location also influences likeliness to collaborate.

Finally, we have begun to develop an approach for comparative, cross-city analysis. We see that homophilic relationships in the key categories we built our analysis upon, network motifs, organizational attributes, neighborhood context, and issue focus, all played a role in explaining collaboration, but in very different patterns across the two cities. Although many of the relationships are similar, there are some key differences. New York seems to have more instrumental patterns, relationships based on the ease of interaction and neighborhood characteristics, and Philadelphia based on social affinity in issues. Building upon the methodology used here with additional replicates across space and over time, we can discern whether or not there are any universal or abiding characteristics in the social and spatial dimensions of civic stewardship networks as well as construct theories about how temporal, social, and geographic contexts affect these structures.

Responses to this article can be read online at: http://www.ecologyandsociety.org/issues/responses. $\mathrm{php} / 11140$ 


\section{Acknowledgments:}

We would like to thank our colleagues Dr. Lara Roman, with the USDA Forest Service Philadelphia Field Station, for providing context on the Philadelphia ERG model results and Dr. Matthew Hamilton for comments on a draft of this article, as well as attendees at the AAG conference in 2018 for comments and suggestions.

\section{LITERATURE CITED}

501c3 Lookup. 2018b. 501c3 Search Results: New York. [online] URL: http://501c3lookup.org/New-York/

501c3 Lookup. 2018a. 501c3 Search Results: Philadelphia. [online] URL: http://501c3lookup.org/Pennsylvania/

Anderson, B. S., C. Butts, and K. Carley. 1999. The interaction of size and density with graph-level indices. Social Networks 21 (3):239-267. https://doi.org/10.1016/S0378-8733(99)00011-8

Atouba, Y. C., and M. Shumate. 2015. International nonprofit collaboration: examining the role of homophily. Nonprofit and Voluntary Sector Quarterly 44(3):587-608. https://doi. org/10.1177/0899764014524991

Bayne-Smith, M., T. Mizrahi, and M. Garcia. 2008. Interdisciplinary community collaboration: perspectives of community practitioners on successful strategies. Journal of Community Practice 16(3):249-269. https://doi.org/10.1080/10705420802255122

Belaire, J. A., A. K. Dribin, D. P. Johnston, D. J. Lynch, and E. S. Minor. 2011. Mapping stewardship networks in urban ecosystems. Conservation Letters 4(6):464-473. https://doi. org/10.1111/j.1755-263X.2011.00200.x

Berardo, R. 2014. Bridging and bonding capital in two-mode collaboration networks. Policy Studies Journal 42(2):197-225. https://doi.org/10.1111/psj.12056

Berardo, R., and J. T. Scholz. 2010. Self-organizing policy networks: risk, partner selection, and cooperation in estuaries. American Journal of Political Science 54(3):632-649. https://doi. org/10.1111/j.1540-5907.2010.00451.X

Bodin, Ö., G. Robins, R. R. J. McAllister, A. Guerrero, B. Crona, M. Tengö, and M. Lubell. 2016. Theorizing benefits and constraints in collaborative environmental governance: a transdisciplinary social-ecological network approach for empirical investigations. Ecology and Society 21(1):40. https://doi. org/10.5751/ES-08368-210140

Bodin, Ö., A. Sandström, and B. Crona. 2017. Collaborative networks for effective ecosystem-based management: a set of working hypotheses. Policy Studies Journal 45:289-314. https:// doi.org/10.1111/psj.12146

Campbell, L. K. 2017. City of forests, city of farms: sustainability planning for New York City's nature. Cornell University Press, Ithaca, New York, USA. https://doi.org/10.7591/9781501714795

Connolly, J. J., E. S. Svendsen, D. R. Fisher, and L. K. Campbell. 2013. Organizing urban ecosystem services through environmental stewardship governance in New York City. Landscape and Urban Planning 109(1):76-84. https://doi.org/10.1016/j.landurbplan.2012.07.001
Connolly, J. J. T., E. S. Svendsen, D. R. Fisher, and L. K. Campbell. 2014. Networked governance and the management of ecosystem services: the case of urban environmental stewardship in New York City. Ecosystem Services 10:187-194. https://doi. org/10.1016/j.ecoser.2014.08.005

Corporation for National and Community Service. 2018b. New York-Northern New Jersey-Long Island, NY-NJ-PA: trends and highlights overview. Corporation for National and Community Service, Washington, D.C., USA. [online] URL: https://www. nationalservice.gov/vcla/city/new-york-northern-new-jersey-longisland-ny-nj-pa

Corporation for National and Community Service. 2018a. Philadelphia-Camden-Wilmington, PA-NJ-DE: trends and highlights overview. Corporation for National and Community Service, Washington, D.C., USA. [online] URL: https://www. nationalservice.gov/vcla/city/philadelphia-camden-wilmington-panj-de

Craig, G. 2007. Community capacity-building: something old, something new...? Critical Social Policy 27(3):335-359. https://doi. org/10.1177/0261018307078846

Diani, M., H. Ernstson, and L. Jasny. 2018. "Right to the city" and the structure of civic organizational fields: evidence from Cape Town. VOLUNTAS: International Journal of Voluntary and Nonprofit Organizations 29(4):637-652. https://doi.org/10.1007/ s11266-018-9958-1

Diez Roux, A. V. 2001. Investigating neighborhood and area effects on health. American Journal of Public Health 91 (11):1783-1789. https://doi.org/10.2105/AJPH.91.11.1783

Ernstson, H., S. Barthel, E. Andersson, and S. T. Borgström. 2010. Scale-crossing brokers and network governance of urban ecosystem services: the case of Stockholm. Ecology and Society 15(4):28. https://doi.org/10.5751/es-03692-150428

Fischer, A. P., and L. Jasny. 2017. Capacity to adapt to environmental change: evidence from a network of organizations concerned with increasing wildfire risk. Ecology and Society 22 (1):23. https://doi.org/10.5751/ES-08867-220123

Fisher, D. R., L. K. Campbell, and E. S. Svendsen. 2012. The organisational structure of urban environmental stewardship. Environmental Politics 21(1):26-48. https://doi.org/10.1080/09644016.2011.643367

Fisher, D. R., and A. M. Galli. 2016. Connecting environmentalism to democracy through environmental stewardship. Revue des Sciences Sociales 55:32-43. https://doi. org $/ 10.4000 /$ revss. 1953

Foster-Fishman, P. G., S. L. Berkowitz, D. W. Lounsbury, S. Jacobson, and N. A. Allen. 2001. Building collaborative capacity in community coalitions: a review and integrative framework. American Journal of Community Psychology 29(2):241-261. https://doi.org/10.1023/A:1010378613583

Freeman, L. C. 1978-1979. Centrality in social networks conceptual clarification. Social Networks 1(3):215-239. https:// doi.org/10.1016/0378-8733(78)90021-7

Gibbs, D., and A. E. G. Jonas. 2000. Governance and regulation in local environmental policy: the utility of a regime approach. 
Geoforum 31(3):299-313. https://doi.org/10.1016/S0016-7185(99) $\underline{00052-4}$

Goodreau, S. M., J. A. Kitts, and M. Morris. 2009. Birds of a feather, or friend of a friend? Using exponential random graph models to investigate adolescent social networks. Demography 46 (1):103-125. https://doi.org/10.1353/dem.0.0045

Granovetter, M. S. 1973. The strength of weak ties. American Journal of Sociology 78(6):1360-1380. https://doi.org/10.1086/225469

Granovetter, M. S. 1977. The strength of weak ties. Pages 347-367 in S. Leinhardt, editor. Social networks: a developing paradigm. Academic, Cambridge, Massachusetts, USA. https://doi. org/10.1016/b978-0-12-442450-0.50025-0

Groce, J. E., M. A. Farrelly, B. S. Jorgensen, and C. N. Cook. 2018. Using social-network research to improve outcomes in natural resource management. Conservation Biology 33(1):53-65. https://doi.org/10.1111/cobi.13127

Hall, P. 1999. Cities in civilization: culture, innovation, and urban order. Phoenix Grant, London, UK.

Handcock, M. S., D. R. Hunter, C. T. Butts, S. M. Goodreau, P. N. Krivitsky, S. Bender-deMoll, and M. Morris. 2016. Statnet: software tools for the statistical analysis of network data. The Statnet Project. [online] URL: http://www.statnet.org

Henning, C., C. Aßmann, J. Hedtrich, J. Ehrenfels, and E. Krampe. 2019. What drives participatory policy processes: grassroot activities, scientific knowledge or donor money? A comparative policy network approach. Social Networks 58:78-104. https://doi.org/10.1016/j.socnet.2019.03.001

Henry, A. D., M. Lubell, and M. McCoy. 2011. Belief systems and social capital as drivers of policy network structure: the case of California regional planning. Journal of Public Administration Research and Theory 21(3):419-444. https://doi.org/10.1093/ jopart/muq042

Howells, J. R. L. 2002. Tacit knowledge, innovation and economic geography. Urban Studies 39(5-6):871-884. https://doi. org/10.1080/00420980220128354

Hyde, C. A., and M. Meyer. 2010. Does attitudinal consensus lead to neighborhood collaboration? An exploratory analysis of an urban community. Journal of Human Behavior in the Social Environment 20(1):56-73. https://doi.org/10.1080/10911350903126932

Ingold, K., and M. Fischer. 2014. Drivers of collaboration to mitigate climate change: an illustration of Swiss climate policy over 15 years. Global Environmental Change 24:88-98. https://doi. org/10.1016/j.gloenvcha.2013.11.021

Jaroff M., D. Frenchman, and F. Rojas. 2009. New century city developments creating extraordinary value. Massachusetts Institute of Technology Press, Cambridge, Massachusetts, USA.

Johnson, M., D. H. Locke, E. Svendsen, L. Campbell, L. M. Westphal, M. Romolini, and J. Grove. 2019. Context matters: influence of organizational, environmental, and social factors on civic environmental stewardship group intensity. Ecology and Society, 24(4):1. https://doi.org/10.5751/ES-10924-240401

Kleinbaum, A. M., T. E. Stuart, and M. L. Tushman. 2013. Discretion within constraint: homophily and structure in a formal organization. Organization Science 24(5):1291-1600. https://doi. org/10.1287/orsc. 1120.0804

Kremer, P., Z. A. Hamstead, and T. McPhearson. 2013. A socialecological assessment of vacant lots in New York City. Landscape and Urban Planning 120:218-233. https://doi.org/10.1016/j. landurbplan.2013.05.003

Lasker, R. D., and E. S. Weiss. 2003. Broadening participation in community problem solving: a multidisciplinary model to support collaborative practice and research. Journal of Urban Health 80(1):14-47. https://doi.org/10.1093/jurban/jtg014

Lee, K., D. J. Harding, and J. D. Morenoff. 2017. Trajectories of neighborhood attainment after prison. Social Science Research 66:211-233. https://doi.org/10.1016/j.ssresearch.2016.12.004

Liedtka, J., and E. Whitten. 1998. Enhancing care delivery through cross-disciplinary collaboration: a case study. Journal of Healthcare Management 43(2):185-205. https://doi. org/10.1097/00115514-199803000-00013

Lubell, M., A. D. Henry, and M. McCoy. 2010. Collaborative institutions in an ecology of games. American Journal of Political Science 54(2):287-300. https://doi.org/10.1111/j.1540-5907.2010.00431. $\underline{\mathrm{x}}$

Lusher, D., J. Koskinen, and G. Robins. 2012. Exponential random graph models for socialnetworks: theory, methods, and applications. Cambridge University Press, Cambridge, UK. https://doi. org/10.1017/CBO9780511894701

Mallach, A., 2018. The empty house next door. Lincoln Institute of Land Policy, Cambridge, Massachusetts, USA. [online] URL: https://www.communityprogress.net/filebin/empty-house-next-door$\underline{\text { full.pdf }}$

McPherson, M., L. Smith-Lovin, and J. M. Cook. 2001. Birds of a feather: homophily in social networks. Annual Review of Sociology 27(1):415-444. https://doi.org/10.1146/annurev.soc.27.1.415

Meyer, M., and C. Hyde. 2004. Too much of a "good" thing? Insular neighborhood associations, nonreciprocal civility, and the promotion of civic health. Nonprofit and Voluntary Sector Quarterly 33(3):77S-96S. https://doi.org/10.1177/0899764004265432

Mountjoy, N. J., E. Seekamp, M. A. Davenport, and M. R. Whiles. 2013. The best laid plans: community-based natural resource management (CBNRM) group capacity and planning success. Environmental Management 52(6):1547-1561. https://doi.org/10.1007/ s00267-013-0169-7

New York Department of City Planning. 2018. MapPLUTO. City of New York, New York, USA. [online] URL: https://www1.nyc. gov/site/planning/data-maps/open-data/dwn-pluto-mappluto.page

Newig, J., D. Günther, and C. Pahl-Wostl. 2010. Synapses in the network: learning in governance networks in the context of environmental management. Ecology and Society 15(4):24. https://doi.org/10.5751/ES-03713-150424

Newman, M. E. J. 2001. Clustering and preferential attachment in growing networks. Physical Review E 64:025102. https://doi. org/10.1103/PhysRevE.64.025102

Open Data Network. 2016. Population density: Philadelphia. Open Data Network. [online] URL: https://www.opendatanetwork. 
com/entity/1600000US4260000/Philadelphia_PA/geographic.population. density?year $=2016$

Park, I. K., and P. Ciorici. 2013. Determinants of vacant lot conversion into community gardens: evidence from Philadelphia. International Journal of Urban Sciences 17(3):385-398. https:// doi.org/10.1080/12265934.2013.818388

ParkScore. 2018b. City profiles: New York. The Trust for Public Land. [online] URL: https://www.tpl.org/city/new-york-newyork

ParkScore. 2018a. City profiles: Philadelphia. The Trust for Public Land. [online] URL: https://www.tpl.org/city/philadelphiapennsylvania

Philadelphia Department of Planning and Development. 2017. Land use. City of Philadelphia, Pennsylvania, USA. [online] URL: http://metadata.phila.gov/\#home/datasetdetails/5543864420583086178c4e74/?view 219 sort=field_15\%7Casc

Pierre, J. 2005. Comparative urban governance: uncovering complex causalities. Urban Affairs Review 40(4):446-462. https:// doi.org/10.1177/1078087404273442

R Core Team. 2017. R: A language and environment for statistical computingitle. R Foundation for Statistical Computing, Vienna, Austria. [online] URL: https://cran.r-project.org/bin/windows/ base/old/3.4.1/

Romolini, M., J. M. Grove, and D. H. Locke. 2013. Assessing and comparing relationships between urban environmental stewardship networks and land cover in Baltimore and Seattle. Landscape and Urban Planning 120:190-207. https://doi. org/10.1016/j.landurbplan.2013.08.008

Sampson, R. J., J. D. Morenoff, and T. Gannon-Rowley. 2002. Assessing "neighborhood effects": social processes and new directions in research. Annual Review of Sociology 28:443-478. https://doi.org/10.1146/annurev.soc.28.110601.141114

Sampson, R. J., S. W. Raudenbush, and F. Earls. 1997. Neighborhoods and violent crime: a multilevel study of collective efficacy. Science 277(5328):918-924. https://doi.org/10.1126/ science. 277.5328 .918

Sayles, J. S., and J. A. Baggio. 2017. Social-ecological network analysis of scale mismatches in estuary watershed restoration. Proceedings of the National Academy of Sciences 114(10):E1776E1785. https://doi.org/10.1073/pnas.1604405114

Schwarz, K., M. Fragkias, C. G. Boone, W. Zhou, M. McHale, J. M. Grove, J. O'Neil-Dunne, J. P. McFadden, G. L. Buckley, D. Childers, et al. 2015. Trees grow on money: urban tree canopy cover and environmental justice. PLoS ONE 10(4):e0122051. https://doi.org/10.1371/journal.pone.0122051

Small, M. L., and M. McDermott. 2006. The presence of organizational resources in poor urban neighborhoods: an analysis of average and contextual effects. Social Forces 84 (3):1697-1724. https://doi.org/10.1353/sof.2006.0067

Smith, D. H. 1994. Determinants of voluntary association participation and volunteering: a literature review. Nonprofit and Voluntary Sector Quarterly 23(3):243-263. https://doi. org/10.1177/089976409402300305
Stokes, R. J., L. Mandarano, and R. Dilworth. 2014. Communitybased organisations in city environmental policy regimes: lessons from Philadelphia. Local Environment 19(4):402-416. https://doi. org/10.1080/13549839.2013.788484

Svendsen, E. S., and L. K. Campbell. 2008. Urban ecological stewardship: understanding the structure, function and management. Cities and the Environment 1(1):1-32.

Svendsen, E. S., L. K. Campbell, D. R. Fisher, J. J. T. Connolly, M. L. Johnson, N. F. Sonti, D. H. Locke, L. M. Westphal, C. L. Fisher, M. Grove, M. Romolini, D. J. Blahna, and K. L. Wolf. 2016. Stewardship mapping and assessment project: a framework for understanding community-based environmental stewardship. General Technical Report 156. U.S. Forest Service, Northern Research Station, Newtown Square, Pennsylvania, USA. https:// doi.org/10.2737/NRS-GTR-156

Swaroop, S., and J. D. Morenoff. 2006. Building community: the neighborhood context of social organization. Social Forces 84 (3):1665-1695. https://doi.org/10.1353/sof.2006.0058

U.S. Census Bureau. 2018a. 2005-2009 5-year American community survey. U.S. Census Bureau, Washington, D.C., USA. [online] URL: https://www.census.gov/programs-surveys/acs/ data/summary-file.2009.html

U.S. Census Bureau. 2018b. 2011-2015 5-year American community survey. U.S. Census Bureau, Washington, D.C., USA. [online] URL: https:/www.census.gov/programs-surveys/acs/ data/summary-file.2015.html

United States Department of Labor Bureau of Labor Statistics. 2018a. Databases, tables \& calculators by subject - Philadelphia unemployment. U.S. Department of Labor Bureau of Labor Statistics, Washington, D.C., USA. [online] URL: https://data. bls.gov/timeseries/LAUCN421010000000003?amp\%253bdata_tool= $\underline{\text { XGtable\&output } \text { view }=\text { data\&include graphs }=\text { true }}$

United States Department of Labor Bureau of Labor Statistics. 2018b. Local area unemployment statistics - New York City. U.S. Department of Labor Bureau of Labor Statistics, Washington, D.C., USA. [online] URL: https://www.bls.gov/regions/newyork-new-jersey/data/xg-tables/ro2xglausnyc.htm

Wandersman, A., R. Valois, L. Ochs, D. S. De la Cruz, E. Adkins, and R. M. Goodman. 1996. Toward a social ecology of community coalitions. American Journal of Health Promotion 10 (4):299-307. https://doi.org/10.4278/0890-1171-10.4.299

Wasserman, S., and K. Faust. 1994. Social network analysis: methods and applications. Vol. 8. Cambridge University Press, Cambridge, UK. 
Missing data in network studies can come in many forms. We can have ties or attribute data reported incorrectly. Additionally, when using survey data, we frequently deal both with non-respondents as well as nodes named as alters who were never included in the sample of respondents. Frequently these nodes are excluded from the analysis (Robins et al. 2012). In this study we decided to take a very different approach. Here, we include the organizations mentioned, thus organizations that have some incoming ties, but are unable to have outgoing ties either because they did not respond to the survey or were never surveyed. Thus, we are able to keep the full structure of the network as described to us by the respondents. However, this adds a lot of missing data; all of the outgoing ties from nonrespondents are missing, although their incoming ties (from respondents), are not. To preserve this structure, we condition the ERG model on this characteristic. We treat the missing ties as 'structural zeros' that we condition on in the modeling procedure. This means that all later statistical tests condition on these ties not being included in the model. We have thus constrained our simulation to replicate the missing data such that it does not influence our statistics. To do so means that we must separate incoming from outgoing ties, as nonrespondents have missing data on the outgoing but not on the incoming ties. For this reason we treat the ties as directed.

\section{References:}

Robins, G., Lewis, J. M., and P. Wang. 2012. Statistical network analysis for analyzing policy networks. Policy Studies Journal 40(3): 375-401. 


\section{Appendix 2: Data Collection and Attribute description}

Data collection and cleaning is, as usual, an arduous task. Organizations were defined in the survey as "a group as having two or more members. This survey is intended for groups and organizations, not for individuals working alone, as sole proprietors, or as independent contractors. If you are a member of a group with multiple programs, please answer for your entire organization. If you are a respondent from a national organization, please answer for your local chapter." Cleaning consisted of getting an accurate list of organizations when referenced differently and combining organizations that were actually sub-organizations of a larger organization. Our quality assurance and data cleaning process dealt with inaccuracies by excluding individuals and by assigning branches/teams/programs to associated organization. Therefore these data are all standardized and cleaned before conducting SNA analysis. This process was the same for both Philadelphia and New York City.

Total respondents for the STEW-MAP survey in each city (New York City, $n=506$; Philadelphia, $\mathrm{n}=195$ ) differs from respondents retained in each city's network model (New York City, $\mathrm{n}=335$; Philadelphia, $\mathrm{n}=151$ ), as not all respondents named network partners. We compared non-respondents to responding organizations by home office location and the type of organization (business, civic, governmental, and school). We saw no clear spatial pattern to the non-responses in either city. For organization type, the numbers of organizations not responding of each category was not significantly different than the organizational distribution of respondents. This was significantly different in New York, however, due to a large number of non-responding civic organizations. From looking at the names, in general these were small community groups. We speculate that this difference was due more to getting additional access to lists of small organizations in New York City than in Philadelphia, and that the actual networks of respondents are still comparable. Future research is planned to take advantage of social media and internet hyperlink data to get at changes in composition over time without relying on respondents. However, our data collection is still an almost an order of magnitude greater than most environmental social network studies (Groce et al. 2018).

There were many instances where respondents also named partners who were not part of the initial survey sample. Attribute information for these organizations was supplemented by internet searches. This additional data collection increased the number of non-respondents in each city (New York City $n=440$; Philadelphia, $n=431$ ). Where many network designs would remove alters that were not included in the survey (Robins et al. 2012), we maintain that including this data is critical for a better understanding of the networks in each city. For collaborating organizations that did not also respond to the survey (i.e., alters), a subset of the same organizational characteristics (501(c)(3) status, staff size, budget, mission, group focus), along with office location addresses, were identified through web searches and phone calls to verify our information. For organizations where home offices were identified, we could then also categorize their home office location according to US Census and land use data. See Appendix 1 for more information on handling the missing data.

Additional variables incorporated into network ERG models were collected from the STEW-MAP datasets and US Census American Community Survey socioeconomic data (2005 - 2009 5-year ACS data for New York City, US Census Bureau 2018a; 2011-2015 5year ACS for Philadelphia, US Census Bureau 2018b). Variables derived from the STEW- 
MAP survey include measures of both the organizational characteristics and neighborhood context. These include attributes of the organizations themselves such as primary focus area, measures of organizational formalization (i.e., staff, membership, volunteers, 501(c)(3) status). We did collect information on the age of the organization, but were unable to get models to converge when this variable was included. This might be due to the high correlations - see Figure A2.1 for correlations between vertex attributes. Paid staff, membership, and volunteers each were recoded as a presence/absence dichotomous variable. To assess neighborhood context, we classified the predominant land use of the census block where the home office was located, and we also used American Community Survey (ACS) data to characterize the census block group. The measures included represent the population density of the block, the median household income, and the median year individuals moved to the block (for residential areas). These variables were also dichotomized by calculating the median of the total observations within each city and coding each block as above (1) or below (0) this median. Finally, spatial measures were included in three ways: (1) distance between office locations, (2) overlap of the stewardship turf where each group has activities, and (3) the geographic extent of each group's stewardship turf (i.e., sub-neighborhood - small; across 2-5 neighborhoods - medium; and larger than 5 neighborhoods - large).

Figure A2.1 shows the correlations between the different vertex attributes (anything pertaining to a specific organization - this contrasts to edge or tie attributes like the distance between home offices). Only the significant correlations, as judged by a $\mathrm{p}<0.05$ from a Pearson Correlation test, are displayed. From the correlation of the variables, we see that Age is negatively correlated with many other organizational attributes in New York City but not Philadelphia. We also see a much tighter correlation in New York City between the Census data for the home office block; in New York City, those with lower than median year moved are more likely to have higher than median household incomes and larger than median population density. These relationships are not seen in Philadelphia. We see many significant correlations between many of the different issue foci (note that Religion is not present in the New York City map as there were too few organizations with that focus to provide meaningful results). We see in both cities a correlation between Environment and Education foci as well as Youth and Seniors. None of the correlations are too high to worry about multicollinearity, and this is confirmed by our VIF tests with no score above 15 (Duxbury 2018). 

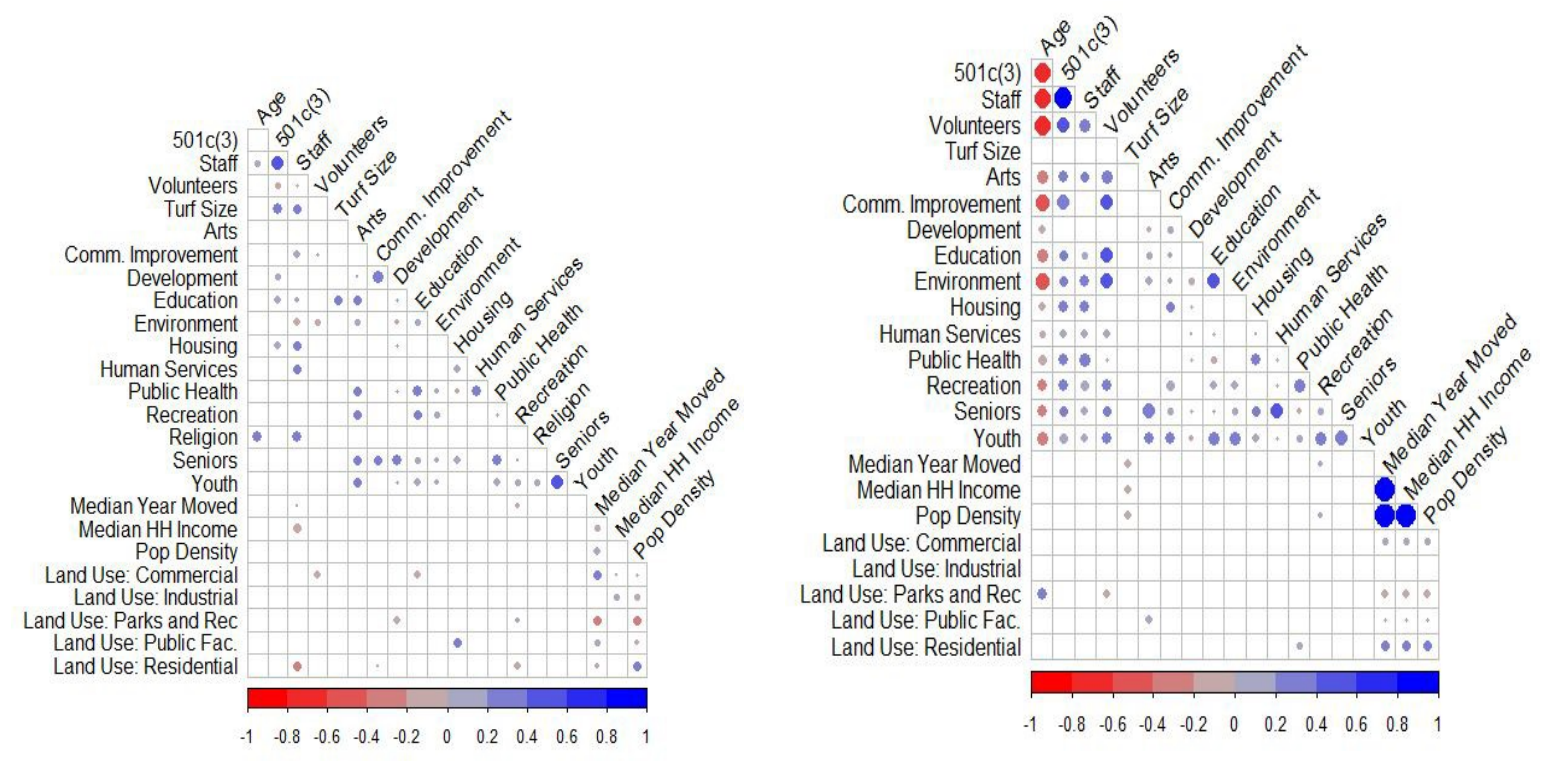

Figure A2.1: Correlation plots for vertex attributes. Philadelphia (left) and New York City (right)

\section{Literature Cited:}

Duxbury, Scott W. 2018. "Diagnosing multicollinearity in exponential random graph models." Sociological Methods \& Research: 0049124118782543.

Groce, J. E., M. A. Farrelly, B. S. Jorgensen, and C. N. Cook. 2018. Using social-network research to improve outcomes in natural resource management. Conservation Biology.

U.S. Census Bureau. 2018a. 2005-2009 5-year American community survey. U.S. Census Bureau, Washington, D.C., USA. [online] URL: https:/www.census.gov/programssurveys/acs/data/summary- file.2009.html

U.S. Census Bureau. 2018b. 2011-2015 5-year American community survey. U.S. Census Bureau, Washington, D.C., USA. [online] URL: https:/www.census.gov/programssurveys/acs/data/summary- file.2015.html 


\section{Appendix 3: Micro-level interpretation of coefficient}

Tables A3.1 and A3.2 show the coefficients and standard errors for every term in 5 different Philadelphia models and A3.3 and A3.4 for New York. Model 5 is the one presented in the full paper, and the terms are presented in the same order as the terms in the figures in the main text. We ran multiple additive models to look at whether these terms improved model fit and also to ensure that we were not over-fitting the data. We use these terms to look at the probability of two organizations collaborating in each city. 


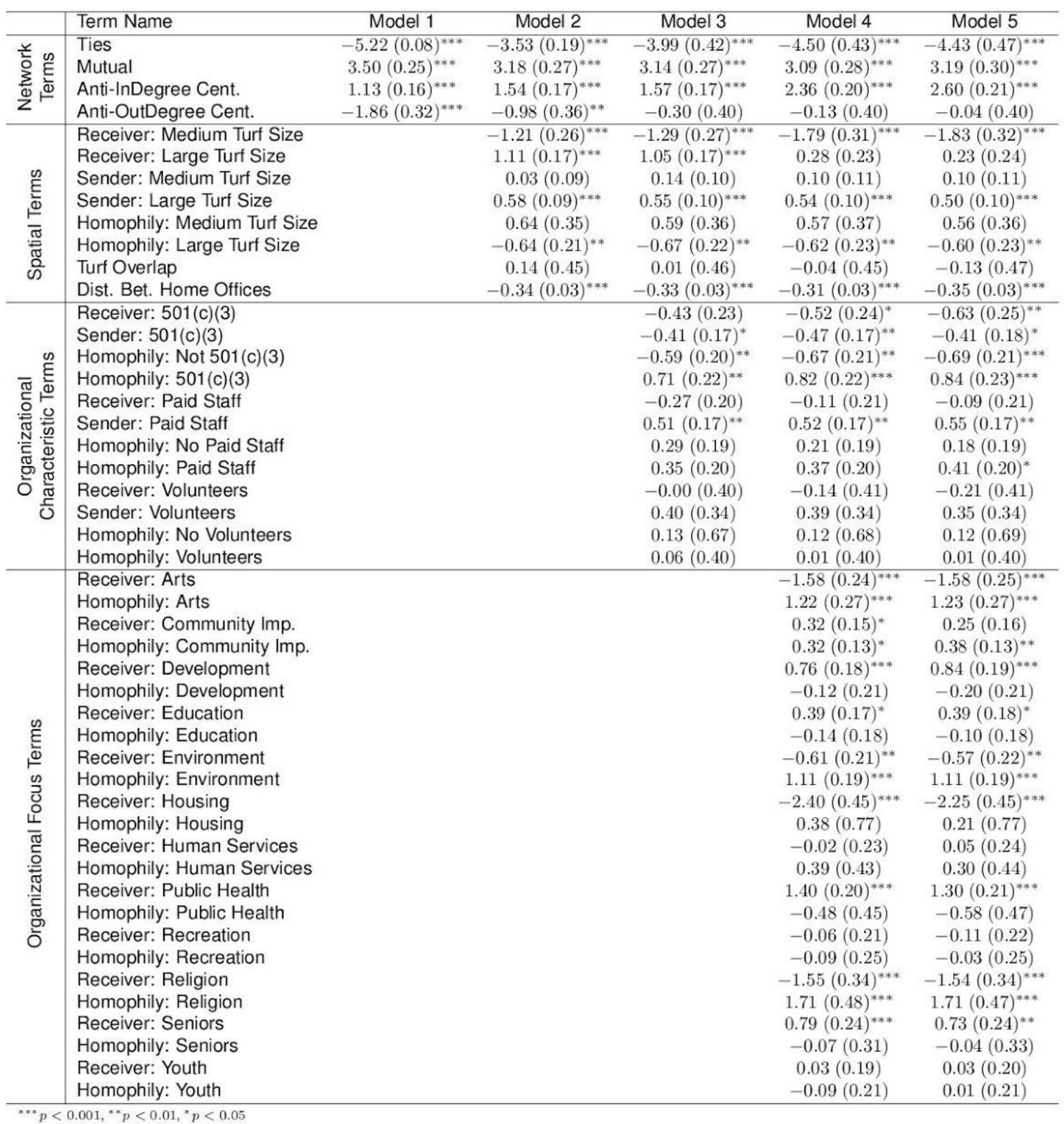

Table A3.1: Philadelphia Models Part 1 


\begin{tabular}{|c|c|c|c|c|c|c|}
\hline & Term Name & Model 1 & Model 2 & Model 3 & Model 4 & Model 5 \\
\hline \multirow{12}{*}{ 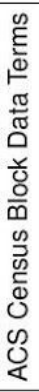 } & Receiver: Later than Median Year Moved & & & & & $0.60(0.19)^{* *}$ \\
\hline & Sender: Later than Median Year Moved & & & & & $-0.46(0.17)^{* * *}$ \\
\hline & Homophily: Earlier than Median Year Moved & & & & & $0.16(0.18)$ \\
\hline & Homophily: Later than Median Year Moved & & & & & $0.02(0.21)$ \\
\hline & Receiver: Higher than Median Household Income & & & & & $0.22(0.17)$ \\
\hline & Sender: Higher than Median Household Income & & & & & $-0.12(0.14)$ \\
\hline & Homophily: Lower than Median Household Income & & & & & $-0.25(0.17)$ \\
\hline & Homophily: Higher than Median Household Income & & & & & $-0.10(0.17)$ \\
\hline & Receiver: Higher than Median Pop Density & & & & & $-0.23(0.20)$ \\
\hline & Sender: Higher than Median Pop Density & & & & & $-0.21(0.16)$ \\
\hline & Homophily: Lower than Median Pop Density & & & & & $0.03(0.18)$ \\
\hline & Homophily: Higher than Median Pop Density & & & & & $0.29(0.18)$ \\
\hline \multirow{17}{*}{ 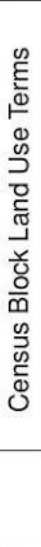 } & Receiver: Industrial & & & & & $-0.09(0.32)$ \\
\hline & Receiver: Parks and Rec & & & & & $0.16(0.25)$ \\
\hline & Receiver: Public Facilities & & & & & $-0.47(0.31)$ \\
\hline & Receiver: Residential & & & & & $0.30(0.18)$ \\
\hline & Receiver: Transportation & & & & & $-0.87(0.48)$ \\
\hline & Sender: Industrial & & & & & $-0.68(0.48)$ \\
\hline & Sender: Parks and Rec & & & & & $-0.66(0.22)^{* * *}$ \\
\hline & Sender: Public Facilities & & & & & $-0.07(0.26)$ \\
\hline & Sender: Residential & & & & & $0.24(0.14)$ \\
\hline & Sender: Transportation & & & & & $-0.72(0.73)$ \\
\hline & Homophily: Commercial & & & & & $-0.75(0.46)$ \\
\hline & Homophily: Parks and Rec & & & & & $-0.19(0.68)$ \\
\hline & Homophily: Public Facilities & & & & & $0.07(1.00)$ \\
\hline & Homophily: Residential & & & & & $-0.17(0.16)$ \\
\hline & $\mathrm{AIC}$ & -111147.86 & -111490.29 & -111578.45 & -111859.35 & -111904.05 \\
\hline & $\mathrm{BIC}$ & -111104.94 & -111361.51 & -111320.91 & -111344.25 & -111109.94 \\
\hline & Log Likelihood & 55577.93 & 55757.14 & 55813.23 & 55977.67 & 56026.02 \\
\hline
\end{tabular}

Table A3.2: Philadelphia Models Part 2 


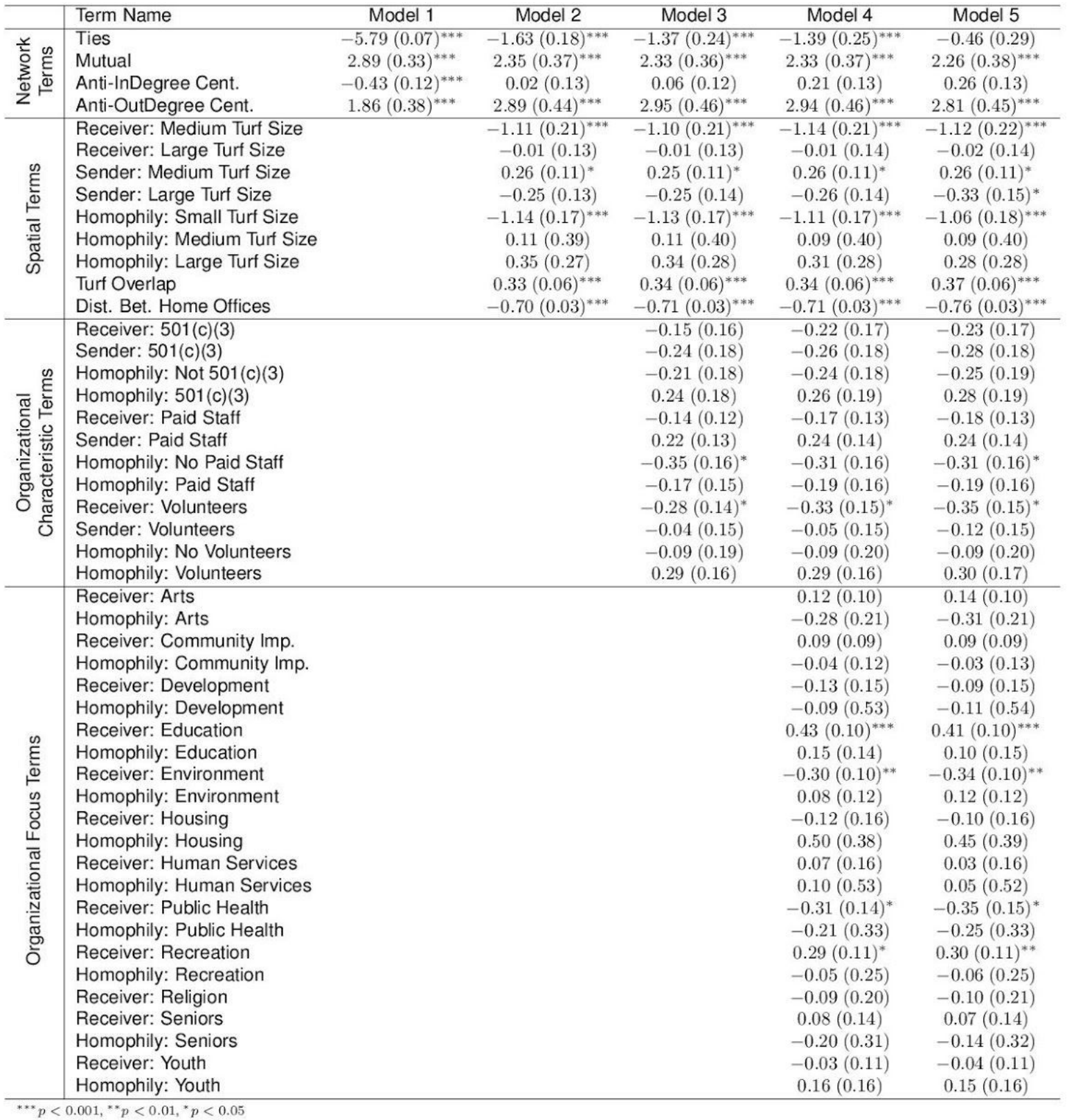

Table A3.3: New York City Models Part 1 


\begin{tabular}{|c|c|c|c|c|c|c|}
\hline & Term Name & Model 1 & Model 2 & Model 3 & Model 4 & Model 5 \\
\hline \multirow{12}{*}{ 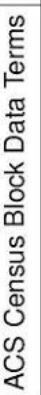 } & Receiver: Later than Median Year Moved & & & & & $0.07(0.13)$ \\
\hline & Sender: Later than Median Year Moved & & & & & $-0.15(0.14)$ \\
\hline & Homophily: Earlier than Median Year Moved & & & & & $0.00(0.16)$ \\
\hline & Homophily: Later than Median Year Moved & & & & & $0.34(0.17)^{*}$ \\
\hline & Receiver: Higher than Median Household Income & & & & & $-0.11(0.13)$ \\
\hline & Sender: Higher than Median Household Income & & & & & $-0.17(0.14)$ \\
\hline & Homophily: Lower than Median Household Income & & & & & $0.14(0.16)$ \\
\hline & Homophily: Higher than Median Household Income & & & & & $0.39(0.16)^{*}$ \\
\hline & Receiver: Higher than Median Pop Density & & & & & $-0.17(0.14)$ \\
\hline & Sender: Higher than Median Pop Density & & & & & $-0.39(0.15)^{*}$ \\
\hline & Homophily: Lower than Median Pop Density & & & & & $-0.14(0.15)$ \\
\hline & Homophily: Higher than Median Pop Density & & & & & $0.43(0.17)^{*}$ \\
\hline \multirow{16}{*}{ 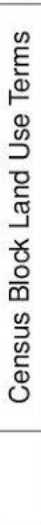 } & Receiver: Industrial & & & & & $-0.51(0.28)$ \\
\hline & Receiver: Parks and Rec & & & & & $0.40(0.16)^{*}$ \\
\hline & Receiver: Public Facilities & & & & & $0.01(0.19)$ \\
\hline & Receiver: Residential & & & & & $-0.34(0.14)^{*}$ \\
\hline & Receiver: Transportation & & & & & $-0.29(0.22)$ \\
\hline & Sender: Industrial & & & & & $0.21(0.29)$ \\
\hline & Sender: Parks and Rec & & & & & $-0.36(0.24)$ \\
\hline & Sender: Public Facilities & & & & & $0.28(0.26)$ \\
\hline & Sender: Residential & & & & & $0.01(0.15)$ \\
\hline & Sender: Transportation & & & & & $0.40(0.20)^{*}$ \\
\hline & Homophily: Commercial & & & & & $-0.57(0.37)$ \\
\hline & Homophily: Parks and Rec & & & & & $0.70(0.40)$ \\
\hline & Homophily: Residential & & & & & $0.07(0.16)$ \\
\hline & AIC & -336221.09 & -337038.79 & -337076.79 & -336976.80 & -337183.47 \\
\hline & $\mathrm{BIC}$ & -336175.87 & -336891.83 & -336794.18 & -336434.19 & -336358.25 \\
\hline & Log Likelihood & 168114.54 & 168532.40 & 168563.40 & 168536.40 & 168664.74 \\
\hline
\end{tabular}

Table A3.4: New York City Models Part 2

Consider two organizations, A and B. B sends a tie to A, and we will consider whether A also sends a tie to B. Both organizations are 501(c)(3) organizations, both have paid staff, but only A has volunteers. Both of their turfs are of medium size, and do overlap. Their home offices are at a distance of 10 kilometers (approximately 6 miles) from each other which works out to -4.71 in logged degrees (the units reported), and both are based in Residential areas with more recently moved residents than the median, higher than the median household income, and a larger population density. Organization A is focused on the Environment and Education, and organization B is focused on the Environment and Recreation. Neither organization has any other ties. For both cities we add up all of the significant coefficients that apply. These are the coefficients in Tables S1 and S2. If we use the standard significance cuttoff of $\mathrm{p}=.05$, then these are the relevant terms with a single star (or more) next to them. In Philadelphia, the significant network terms are Ties (-4.43), Mutual (3.19), and Anti-InDegree Centralization (2.60). The last term is a geometrically weighted term, but as adding a tie from A to $B$ increases the in-degree centralization only of B from 0 to 1 , we do not need to include the weighting (see Levy 2016 for more information). All of these terms are relevant to the tie from $\mathrm{A}$ to $\mathrm{B}$ as this will be a mutual tie given that B already says they collaborate with $\mathrm{A}$.

Network Terms contribution in Philadelphia:

$$
-4.43+3.19+2.60=1.36
$$

We can examine the same terms in New York. As adding a term from A to B will increase the out-degree of A from 0 to 1, we similarly can include the Anti-OutDegree Centralization term for New York just as we treated Anti-InDegree Centralization for Philadelphia. Also 
note that here the ties term is not signficant. Thus, the Network terms contribution for New York City is given below.

Network Terms contribution in New York:

$$
2.26+2.81=5.07
$$

We cannot directly compare these numbers until we add up everything else relevant to the particular organizations. These numbers would be appropriate only for organizations where no other terms applied. Turning to the Spatial Terms, since both organizations have medium sized turfs, the negative and significant Sender and Receiver: Medium Turf Size terms in both cities apply. The homophily term is not significant in either city, so it is not included. Turf Overlap is significant for New York, so we include that coefficient (0.99) for New York. The term Distance Between Home Offices is significant in both cities so it will be included. The coefficient for this term is multiplied by the log of the actual distance (in geographic degrees) between the home offices. Thus, the Spatial Terms contribution for each city is:

Spatial Terms contribution in Philadelphia:

$$
-1.83+0.50+(-4.71) *(-0.35)=0.32
$$

Spatial Terms contribution in New York:

$$
-1.12+0.26+0.37+(-4.71) *(-0.76)=3.09
$$

For the Organizational Characteristics Terms, we see a lot of difference between significance in Philadelphia and New York. In Philadelphia the Sender and Receiver: 501(c)(3) and Homophily: 501(c)(3) terms apply as well as Sender: Paid Staff and Homophily: Paid Staff. For New York, only Receiver: Volunteers applies.

Organizational Characteristics Terms contribution in Philadelphia:

$$
-0.63+(-0.41)+(0.69)+0.55+0.41=0.61
$$

Organizational Characteristics Terms contribution in New York:

$$
-0.35
$$

Organization A is focused on the Environment and Education, and organization B is focused on the Environment and Recreation. In Philadelphia, Receiver: Environment, and Homophily: Environment are all significant terms. In New York, Receiver: Environment and Receiver: Recreation are also significant. Thus the Organizational Focus Terms contribution is:

Organizational Focus Terms contribution in Philadelphia:

$$
(-0.57)+1.11=0.54
$$

Organizational Focus Terms contribution in New York:

$$
(-0.34)+0.30=-0.04
$$

There are no contributions form the ACS data terms for Philadelphia. In New York City, the significant effects areHomophily: Later than Median Year Moved, Homophily: Higher than Median Household Income, Sender: Higher than Median Pop Density, and Homophily: Higher than Median Pop Density.

ACS Census Block contribution in Philadelphia: 
ACS Census Block contribution in New York:

$0.34+0.39+(-0.39)+(0.43)=0.77$

Finally, there are no significant terms for having home office locations in Residential areas in the model for Philadelphia, whereas Receiver: Residential is significant in New York. Thus,

Census Block Land Use contribution in Philadelphia:

0

Census Block Land Use contribution in New York:

$-0.34$

Adding up all these contributions for each city gives an overall log-odds of the tie from Organization A to B in Philadelphia of 2.83. Taking the inverse logit, we find the overall probability of this tie occurring to be roughly $94 \%$. In New York, the total logodds is 8.2 yielding a probability of $99.97 \%$. Because we selected for different types of homophily in each city combined with the centralization effects we get a huge chance of each tie, but for different reasons. We therefore see differences in how these coefficients play out when combined appropriately in the two different cities.

References:

Levy, M. A. 2016. gwdegree: Improving interpretation of geometrically-weighted degree estimates in exponential random graph models. Journal of Open Source Software 1(3): 36. 


\section{Appendix 4: Goodness of fit}

In ERG models, goodness of fit is essential for whether or not the model results can be interpreted (Hunter et al. 2008). The figures below (A4.1, A4.2) show goodness of fit information for the two models presented in the paper. The thick line shows the p-value for the empirical data compared to box-plots from 1000 simulations. The relative approximation of the empirical data by the simulations show that the models converged well and the results can be interpreted.

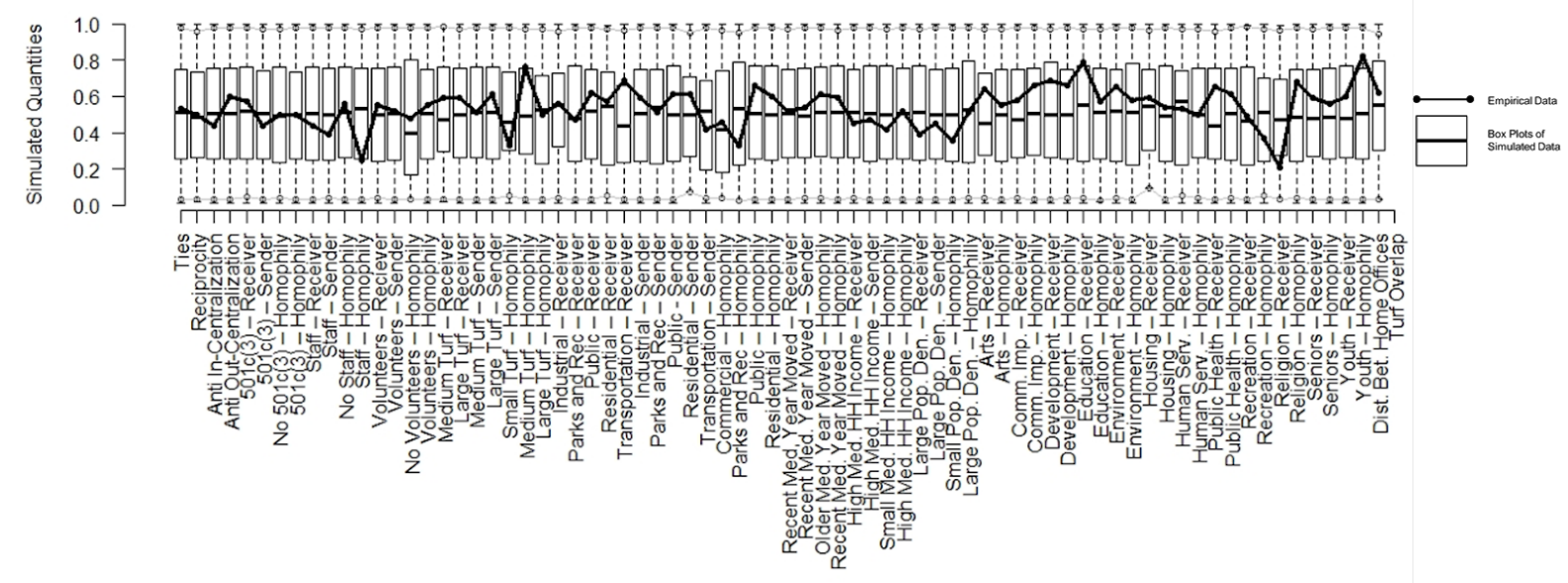

Figure A4.1: Goodness of Fit for Philadelphia

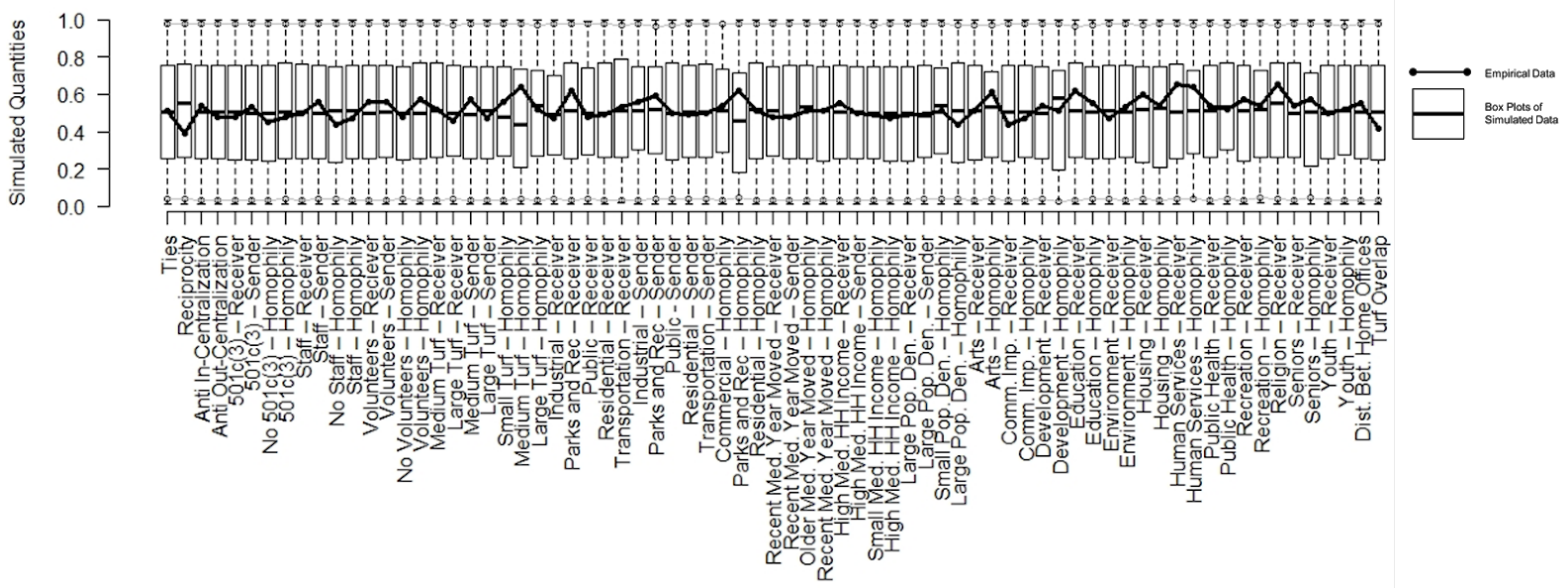

Figure A4.2: Goodness of Fit for New York

References:

Hunter, D. R., Goodreau, S. M., and M. S. Handcock. 2008. Goodness of fit of social network models. Journal of the American Statistical Association 103(481):248-258 